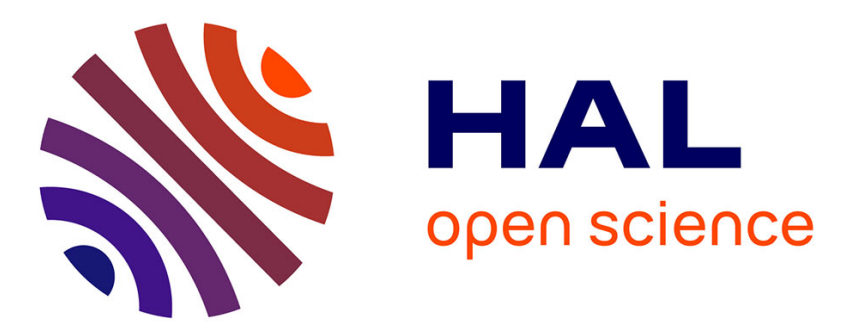

\title{
Structural multi-modal damping by optimizing shunted piezoelectric transducers
}

Stéphanie Livet, Manuel Collet, Marc Berthillier, Pierrick Jean, Jean Cote

\section{To cite this version:}

Stéphanie Livet, Manuel Collet, Marc Berthillier, Pierrick Jean, Jean Cote. Structural multimodal damping by optimizing shunted piezoelectric transducers. Revue Européenne de Mécanique Numérique/European Journal of Computational Mechanics, 2011, 20 (1-4), pp.73-102. 10.3166/ejcm.20.73-102 . hal-02300138

\section{HAL Id: hal-02300138 \\ https://hal.science/hal-02300138}

Submitted on 7 Apr 2021

HAL is a multi-disciplinary open access archive for the deposit and dissemination of scientific research documents, whether they are published or not. The documents may come from teaching and research institutions in France or abroad, or from public or private research centers.
L'archive ouverte pluridisciplinaire HAL, est destinée au dépôt et à la diffusion de documents scientifiques de niveau recherche, publiés ou non, émanant des établissements d'enseignement et de recherche français ou étrangers, des laboratoires publics ou privés.

\section{(c)(1)}

Distributed under a Creative Commons Attribution| 4.0 International License 


\section{Structural multi-modal damping by optimizing shunted piezoelectric transducers}

\section{Stéphanie Livet* - Manuel Collet** _ Marc Berthillier** Pierrick Jean* _ Jean-Marc Cote**}

* Snecma, SAFRAN Group

Rond-Point René Ravaud-Réau

F-77550 Moissy Cramayel

stephanie.livet@gmail.com

** Femto-ST Institute, Applied Mechanics Dpt

24 rue de l'Epitaphe

F-25000 Besançon

manuel.collet@univ-fcomte.fr

ABSTRACT. The capacity of different auto-supplied devices using shunted piezoelectric circuits are studied here to improve structural damping by avoiding implementation of complex and heavy control devices. The presented technique uses a dedicated numerical piezo-mechanical model combining both mechanical and electrical coupling parameters. An original methodology are also introduced for optimizing the parameters of electrical shunt circuits connected to piezoelectric elements and also structural locations of these integrated transducers. The results, experimentally validated (on beams and a plate), demonstrate that vibrations can be significantly reduced when shunted piezoelectric devices are mounted on a real structure. Finally, the proposed methodology is used for optimizing shape and location of the shunted piezoelectric patches to damp several modes of a plate.

RÉSUMÉ. Cet article présente les outils de conception, d'analyse et de validation expérimentale de systèmes de contrôle semi-actif basés sur l'utilisation de shunts électriques connectés à des patchs piézoélectriques. Basée sur une modélisation dédiée à l'analyse des systèmes couplés, une méthodologie originale est alors introduite pour optimiser les paramètres des circuits électriques et également la localisation sur la structure de ces transducteurs intégrés. Les résultats, validés expérimentalement, montrent que les niveaux vibratoires peuvent être considérablement réduits par l'introduction de shunts électriques. Enfin, la méthodologie proposée est utilisée pour optimiser la forme et l'emplacement des patchs piézoélectriques shuntés pour amortir plusieurs modes d'une plaque dont la dynamique est comparable à celle d'une aube de turbine.

KEYWORDS: piezoelectricity, shunt circuit design, semi-active control, damping optimization. MOTS-CLES : piézoélectrique, optimisation électro-mécanique, amortissement semi-actif. 


\section{Introduction}

Research activities in smart materials and structures are very important today and represent a significant potential for technological innovation in mechanics and electronics. The growing interest of our society in the problem of sustainable development compels a broad research effort for optimizing mechanical structures in order to obtain new functional properties such as noise reduction, comfort enhancement, durability, performances, decreased ecologic impact, etc. (Becker, Fein, Maess et Gaul 2006). Over the past 30 years, a great deal of attention has focused on the active control of noise, vibration and structural response (Nelson et Elliott 1992, Preumont 1997). Active control of mechanical structures commonly involves feedback strategies based on the use of a small number of transducers. We can find in the literature many studies concerning the adaptation of standard automation tools for structural stabilization and isolation. One of the key points of interest has been the optimization of the location and shape of semi-distributed transducers such as piezoelectric patches or stacks. Collocated and non-collocated strategies have also been widely studied and compared in order to deal with the specific problem encountered when controlling continuous structures with an infinite number of degrees of freedom. The book of A. Preumont (Preumont 1997) presents a comprehensive overview of this arena, emphasizing the implementation efficiency but also the limiting problems such as spill-over, robustness, localized efficiency, etc.

Some particular structures such as rotors or gas-turbine blades are particularly sensitive to aero-elastic coupling phenomena. The induced aerodynamic limits can be pushed away by adding extra damping to the structure in order to reach even better performances. The main design constraint is also to improve stability while limiting additional weight. In order to realize such a multi-objective design, new methods are now available which allow active transducers and their driving electronics to be directly integrated into otherwise passive structures. The number of potential specific applications for these approaches is growing significantly in many industrial fields such as civil engineering, aerospace, aeronautics, ground transportation, etc. The main research challenge today deals with the development of new multi-functional structures integrating electro-mechanical systems in order to optimize their intrinsic static or load-bearing mechanical behavior while also achieving goals specific to their dynamic response. In this new technological environment, another very promising way to optimize the vibroacoustic behavior of complex continuous systems is to use distributed approaches. This strategy is based on using a semi-distributed set of transducers able to impose upon a part of the mechanical system, an implementation of a controlling operator. The technological revolution of these past few years in the field of integrated Micro Electro Mechanical Systems give us a real potential to realize this next generation of smart structures. We know today that the mechanical integration of active smart materials, electronics, chip sets and power supply systems is possible for these smart "composite" structures. By using such an integrated active or hybrid distributed set of electromechanical transducers, we could also attain the desired new functionalities. In this sense, we can speak of "integrated distributed smart struc- 
tures." Some works in this regard can be found in (Tanaka et Kikushima 1999, Tanaka et Sakano 2007).

To deal with this new scientific and technological challenge, shunted piezoelectric systems offer a very attractive path for electro-mechanical integration and distribution. Numerous works have been published (Park et Palumbo 2004, Becker et al. 2006, Hagood et von Flotow 1991, Agnes 1994, dell' Isola, Maurini et Porfiri 2004, Moheimani et Fleming 2006, Cross et Fleeter 2002, Beck, Cunefare et Ruzzene 2008) that present analysis of the capability and efficiency of a single shunted piezoelectrical patch for structural stabilization and wave cancellation. With this approach, the sensing element is not needed and the use of a passive network guarantees the stability of the coupled system. Hagood and VonFlotow (Hagood et al. 1991) provided the first analytical formulation for passive shunt networks. They demonstrated how a piezoelectric patch shunted through a single resistive-inductive (RL) circuit acts as a vibration absorber tuned at the resonance frequency of the circuit. Since then, more complex shunting circuits have been investigated to extend the effectiveness over broader frequency bands. For example, multi-mode techniques have been proposed by (Wu et Bicos 1997) who employed a series of blocking, inductive-capacitive (LC) circuits in parallel with an RL shunt circuit designed to attenuate a specific resonance frequency. Other methods of broadband suppression include state switching (Corr et Clark 2002), synthetic impedance (Fleming, Belirens et Moheimani 2000), and negative impedance circuits (Behrens, Fleming et Moheimani 2001, Park et al. 2004, Park et Baz 2005, Fukada, Date et Kimura 2002). The selection of negative impedance shunt parameters have been chosen by a few different tuning theories. Behrens selected the shunt parameters through investigation of the active control element of the negative capacitance (Behrens et al. 2001). Park and Palumbo decomposed the wave field on a beam to find a minimization of the reflected wave component (Park et al. 2004). By noticing the link between the wave based approach of Park and Palumbo and the power input to the system, Cunefare developed a parameter selection technique based on the reactive input power (Cunefare 2006). Negative capacitance shunts can be designed to work in conjunction with piezoelectric patches arrayed in a periodic fashion. Periodic structures have been shown to improve the broadband performance of control systems on structures (Casadei, Beck et Ruzzene 2009, Thorp, Ruzzene et Baz 2001). On all these works, piezoelectric shunt damping also appears as promising passive technique for vibration control of flexible structures (Beck et al. 2008, Cunefare 2006). Contrary to active control, the only external element to be used is a passive electrical network (PEN) that is directly connected to the electrodes of the piezoelectric device.

These techniques allow to use a perfectly collocated system of transducers to control the mechanical structure. Thus, we can profit of the poles/zeros interlacing theorem to guarantee robust stability of the control system (Preumont 1997). Furthermore, the analogical electrical circuits used for shunting the piezoelectric patches, do not introduce a large additional mass into the system nor a large time delay and also can be implement for a large frequency band. Depending onto the used shunt circuits, the necessary large reactive part of the electrical circuit can be obtained by using suit- 
able synthetic inductance or capacitance implying operational amplifiers (Fleming, Behrens et Moheimani 2003, Fleming et Moheimani 2004).

Based on these works, this paper is focused on optimizing the fully electromechanical parameters behavior of shunted piezoelectric transducers for structural stabilization in a multi modal context. For designing the piezo-mechanical system one can use the the modal effective electromechanical coupling coefficient, proposed in (Chevallier, Ghorbel et Benjeddou 2008). However, no closed form tuning solution has been found for these techniques and numerical optimization is the only way to simultaneously determine the values for the electrical components when several modes are taken into configuration. Thus, for the control of a large number of modes, numerical optimization may result in a complicated procedure, and the implementation of the circuit may become a difficult task due to the high order of the system. For designing the piezo-mechanical system one can use the the modal effective electromechanical coupling coefficient, proposed in (Chevallier et al. 2008).

This paper first presents a study of the induced phenomena and explain the influence of the piezoelectric component in the energy transfer between the schematically modeled structure and different electronic circuits. Based on the work of (Preumont 1997, Monnier, Collet et Piranda 2004, Chevallier et al. 2008), optimization guidelines is highlighted to maximize the induced structural damping for multimodal stabilization. In a second part, experimental tests has been settled to verify theoretical results on damping with semi-passive shunts as resistance and negative capacitance. The sensitivities of the induced modal damping ratios on shunt circuit, piezoelectric materials and the parameters of the patch geometry are studied. We also quantify the capability of the introduced semi-passive shunted piezoelectric system to stabilize the vibrating structure and check how much the studied integrated piezoelectric system can likely damp complex mechanical system without a need of external power supply. Finally, an optimization procedure is proposed for shaping and locating the piezoelectric patches glued onto a plate and designing the electronic circuit components in view of stabilizing a plate supporting structure on its first modes. Experimental validation is also carried out to validate the proposed methodology.

\section{Piezoelectric modeling and shunt circuit design}

Let us consider a very simple system constituted of a single piezoelectric patch glued onto a supporting beam as described in Figure 1. The piezoelectric material is assumed to be polarized along positive $(O z)$ direction. The bottom electrode (interface between piezoelectric domain and the support) is grounded.

\subsection{Modeling aspects}

Different modeling approaches can be used for describing such systems. The survey paper of (Benjeddou 2000), and the papers (Noor 1991) and (Mackerle 1997) 


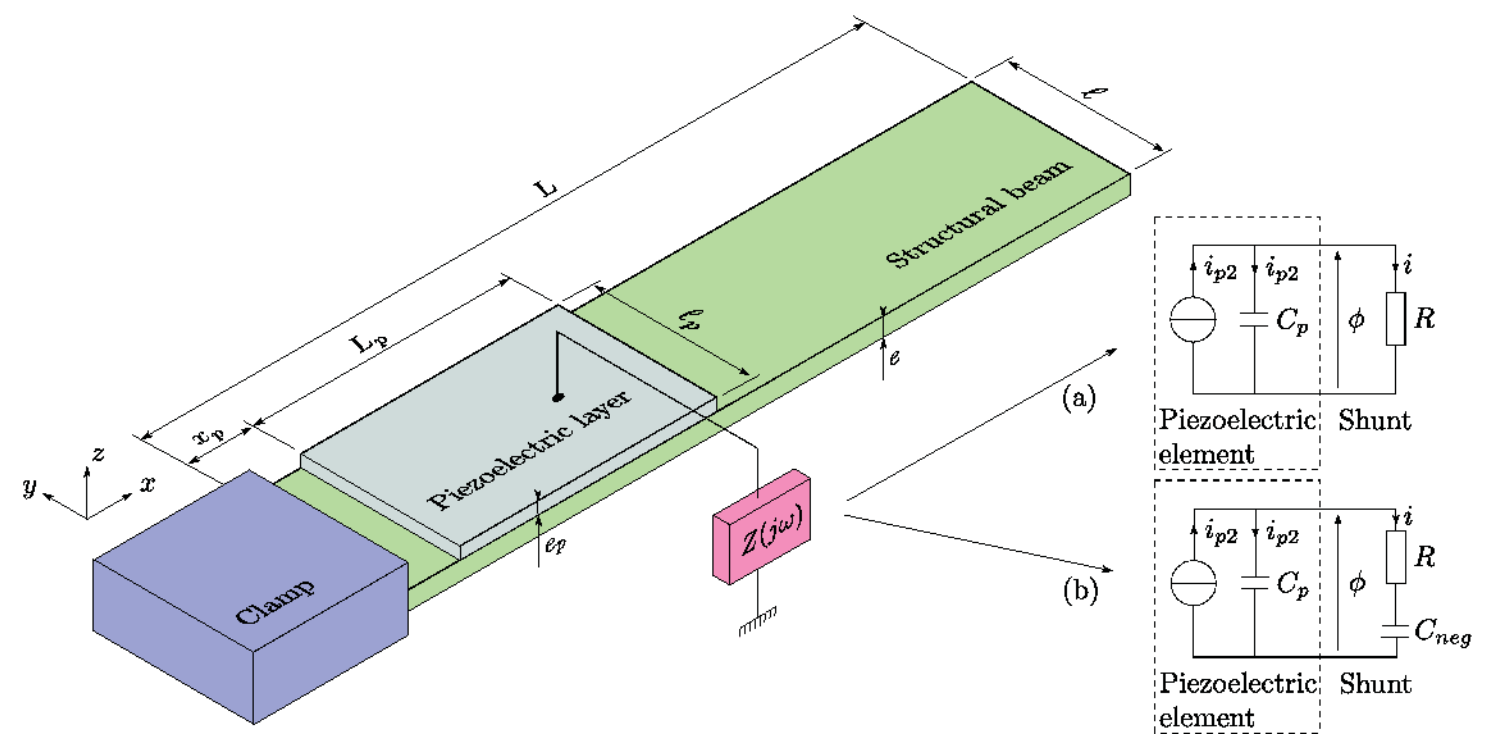

Figure 1. Schematic of a used piezo composite beam. a/ shunted with a resistive $(R)$ circuit; $b /$ shunt with $R$ and negative capacitance (RCneg) circuit

analyze a wide variety of different works in this area. A numerous of piezoelectric finite elements methods for sandwich beams (Collet, Walter et Delobelle 2003, Maurini, dell'Isola et Pouget 2004), plates (Ha 1990, Wang 2004, Kogl et Bucalem 2005, Fernadez et Pouget 2004, Tzou et Fu 1994a, Tzou 1997, Lee 1990, Lee et Moon 1989, Lee, Chiang et O'Sullivan 1991, Banks, Smith et Wang 1996, Saravanos, Heyliger et Hopkins 1997), layered composite shells (Yang, Saigal et Liaw 1996, Kogl et al. 2005, Bernadou et Haenel 2003, Banks et al. 1996) or volume elements, as those used in many finite element codes (Varadan, Lim et Varadan 1996, Lin, Abatan et Rogers 1994, Tzou 1997) can be found in literature.

As noted in (Benjeddou 2000, Collet et Cunefare 2008), the most theoretically advanced finite elements has not been widely used for practical modeling of adaptive structural elements for "intelligent" or smart materials and structure applications. Because of the difficulty of building accurate and reduced models for multiphysics analysis, many authors use simplified modeling approaches in order to limit numerical complexity while focusing on physical design, computation and optimization (Rao et Sunar 1994, Crawley 1994, Preumont 1997, Monnier et Collet 2005, Hagood et al. 1991, Collet 2001).

Modeling of standard piezoelectric problem is based on writing two sets of partial derivative equations and their associated boundary conditions for introducing the elastodynamic equilibrium and in the other one the electrostatic one. A synthetic form of the $3 \mathrm{D}$ electromechanical dynamical equilibriums can be written as

$$
\begin{cases}\rho \ddot{w}-\nabla \sigma=f & \forall x \in \Omega \cup \Omega_{p} \\ -\nabla D=0 & \forall x \in \Omega_{p}\end{cases}
$$


with a linear piezoelectric constitutive equations so as:

$$
\begin{aligned}
\sigma & =c_{E}(x) \epsilon-e^{T}(x) E \\
D & =e(x) \epsilon+\varepsilon_{S}(x) E
\end{aligned}
$$

where $\sigma$ represents the Cauchy stress tensor, $\epsilon=\nabla_{\text {sym }} w$ the Green strain tensor, $E=-\nabla V$ the electric field vector ( $V$ the voltage), $D$ the charge displacement, $\rho$ the mass density, $w$ the displacement vector, $C_{E}$ the elasticity tensor at constant electrical field, $e^{T}$ the piezoelectric coupling tensor and $\varepsilon_{S}$ the dielectric permittivity at constant strain. Combining Equations [2], [3] and [1] leads to the standard general form of the set of partial differential equations describing the dynamic equilibrium of such coupled problem.

To obtain a simple weak formulation limiting the numerical cost to treat the coupled problem, the classically used assumption, applied in most of the finite elements codes, is to consider through-thickness linear variation of the electrical potential (Collet et al. 2003, Preumont 1997, Hagood et al. 1991, Hac et Liu 1993, Tzou et $\mathrm{Fu}$ 1994b). This hypothesis leads to neglect the induced potential, while the electromechanical coupling will be only partially captured as described in (Benjeddou 2000, Collet et al. 2008, Chevallier et al. 2008). This approach can yield up to $30 \%$ error in evaluating the equivalent piezoelectric capacity for small patches. In fact, it is known that the asymptotic electric potential for a short-circuited thin plate is quadratic in the thickness (Bernadou et al. 2003).

In this paper, we use two different modeling approaches: one using this standard assumption, which is a 1D composite beam modeling as described in (Collet et al. 2003, Hac et al. 1993, Tzou et al. 1994b), and a second one using a full 3D approach based on the methodology proposed in (Collet et al. 2008).

\subsection{Electric shunt design parameter}

Whatever the modeling approach is, we always obtain a discretized system of the form:

$$
\begin{aligned}
M \ddot{w}(t)+C \dot{w}(t)+K w+\boldsymbol{e}_{\boldsymbol{w} \boldsymbol{v}} V(t) & =F(t) \\
-\boldsymbol{e}_{\boldsymbol{w} \boldsymbol{v}}^{T} w(t)+C_{p}^{S} V(t) & =Q(t)
\end{aligned}
$$

where $M, K, C$ stand respectively for mass, damping and open circuit stiffness matrices, $e_{w v}$ is the piezoelectric coupling matrix depending on piezoelectric material coefficients $e$ but also on geometric and support characteristics, $C_{p}^{S}$ is the diagonal matrix of each equivalent piezoelectric capacitances for zero strain. $w$ represents the vector of mechanical degrees of freedom and $V$, the vector of the applied upper electrode voltage, whereas $Q$ is the dual measured current. The main difference between 
the full (or well condensed) 3D and the simplified beam or plate approaches is located in evaluation of $C_{p}^{S}$ and $\boldsymbol{e}_{\boldsymbol{w} \boldsymbol{v}}$ matrices.

When optimizing shunt circuit for stabilizing that dynamical system, you have to design the suitable electrical relationship (i.e the circuit) by generically finding optimal parameters of ordinary differential equations linking applied voltage $V$ and the produced current $Q$ so that: $\sum_{i=0}^{N} a_{i} \frac{d^{i} V(t)}{d t^{i}}=\sum_{j=0}^{P} b_{j} \frac{d^{j} Q(t)}{d t^{j}}$. Let us consider only two simple electronic circuits:

- A resistive circuit for which

$$
V(t)=-R \frac{d Q(t)}{d t}
$$

that is represented in Figure 1.a;

- a serial resistance/capacitance circuit for which

$$
V(t)=-\left(\frac{Q(t)}{C_{n e g}}+R \frac{d Q(t)}{d t}\right)
$$

represented on Figure 1.b.

We do not consider resonant RL shunts circuit but the feedback's expression can also be written as an ordinary differential equation as in Equations [6] and [7]. For more precisions on this approach, reader would refer to (Hagood et al. 1991, Moheimani et al. 2006, Fleming et al. 2003, Moheimani, Fleming et Behrens 2001).

\subsubsection{Resistive shunt circuit}

Let us consider a simple resistive circuit. Equations [4] [5] and the feedback term can also be rewritten as:

$$
\begin{aligned}
M \ddot{w}(t)+C \dot{w}(t)+\left(K+\boldsymbol{e}_{\boldsymbol{w} \boldsymbol{v}}^{T}\left(C_{p}^{S}\right)^{-1} \boldsymbol{e}_{w \boldsymbol{v}}\right) w(t)= & -\boldsymbol{e}_{\boldsymbol{w} \boldsymbol{v}}\left(C_{p}^{S}\right)^{-1} Q(t) \\
& +F(t) \\
\left(C_{p}^{S}\right)^{-1} Q(t)+\left(C_{p}^{S}\right)^{-1} \boldsymbol{e}_{\boldsymbol{w} \boldsymbol{v}}^{T} w(t)= & V(t) \\
-\frac{1}{R} \int V(t) d t= & Q(t)
\end{aligned}
$$

In that case, we obtain a typical system of ordinary differential equation corresponding to the implementation of an Integral Force Feedback strategy. This active damping control is well described in (Monnier et al. 2004, Preumont 1997). Thus all design parameters and optimization criteria are well known since the nineties. When $\frac{1}{R}$ take all values in $\mathbb{R}^{+}$, each complex eigen values of the obtained dynamical system follows a well known root locus depicted on Figure 2. For lightly coupled system (see (Monnier et al. 2004) for definition), the maximum induced damping ratio for a given mode $i$ is given by :

$$
\xi_{i}^{\max }=\frac{\omega_{o c_{i}}-\omega_{s c_{i}}}{2 \omega_{s c_{i}}}
$$


where $\omega_{o c_{i}}$ corresponds to open circuit eigen frequencies (i.e the solutions of $\left.\left(-\omega_{o c_{i}}^{2} M+\left(K+e_{w v}^{T}\left(C_{p}^{S}\right)^{-1} e_{w v}\right)\right) \phi_{i}^{o c}=0\right)$ and $\omega_{s c_{i}}$, the zeros of system represented in Equations [9],[10], that is to say the short circuit eigen frequencies (i.e the solutions of $\left.\left(-\omega_{s c_{i}}^{2} M+K\right) \phi_{i}^{s c}=0\right)$.

The piezoelectric coupling coefficient is primarely defined in (IEEE 1988). The proposed definition is based on computing of the energy efficiency in piezolectric transfer for a defined static loading cycle. From a physical point of view, the obtained coupling factor characterize material efficiency for transferring mechanical energy into electrical one and vice-versa and there for standard loading cases. When dynamical responses of complex systems, including piezoelectric materials, are considered, one prefers to speak about the effective modal coupling coefficients $k_{e f f_{i}}$ defined in (Chevallier et al. 2008, Collet et al. 2008). It is defined as $k_{e f f_{i}}^{2}=\frac{\omega_{o c_{i}}^{2}-\omega_{s c_{i}}^{2}}{\omega_{s c_{i}}^{2}}$. If one considers a low piezoelectric coupling effect meaning that the piezoelectric patch lightly modifies the corresponding structural eigenfrequency $\left(\omega_{i}\right)$, one can demonstrate that $\frac{\omega_{o c_{i}}+\omega_{s c_{i}}}{2} \approx \omega_{i}$. So, under this assumption, $k_{e f f_{i}}^{2} \approx \frac{\omega_{o c_{i}}^{2}-\omega_{s c_{i}}^{2}}{\omega_{i}^{2}}$ is a first order approximation of the modal effective electromechanical coupling coefficient.

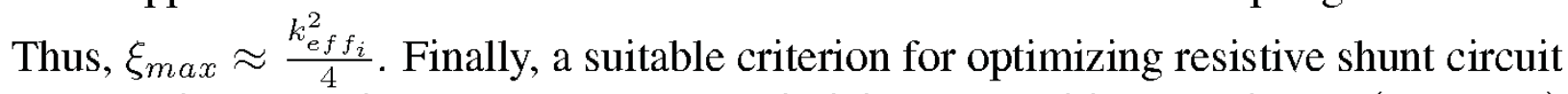
for damping a specific mode $i$ can be maximizing the positive function $\Theta_{i}\left(L_{p}, x_{p}, e\right)$ defined as :

$$
\Theta_{i}\left(L_{p}, x_{p}, e\right)=\omega_{o c_{i}}^{2}-\omega_{s c_{i}}^{2}
$$

The form is directly linked to eigen value computation and avoid any singularity problems that can occur when one tries to directly optimize $k_{e f f_{i}}^{2}=\frac{\omega_{o c_{i}}^{2}-\omega_{s c_{i}}^{2}}{\omega_{s c_{i}}^{2}}$ or $\xi_{i}^{\max }$.

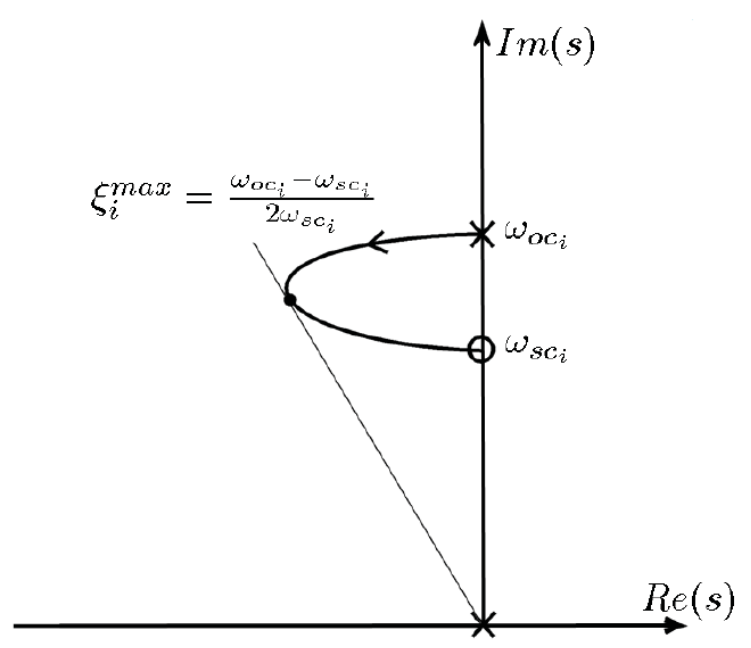

Figure 2. Root locus induced by a resistive shunt circuit 


\subsubsection{Negative capacitance circuit}

If we now consider a serial $R C_{n e g}$ shunt circuit, based on the system equilibrium Equations [4] [5] and the electronic introduced feedback, the controlled equations are:

$$
\begin{aligned}
M \ddot{w}(t)+C \dot{w}(t)+\cdots & \\
\left(K+e_{w v}^{T}\left(C_{p}^{S}+C_{n e g}\right)^{-1} e_{w v}\right) w(t)= & -e_{w v} \frac{C_{n e g}}{C_{n e g}+C_{p}^{S}} V(t) \\
& +F(t) \\
-e_{w v}^{T} \frac{C_{n e g}}{C_{n e g}+C_{p}^{S}} w(t)+C_{p}^{S} \frac{C_{n e g}}{C_{n e g}+C_{p}^{S}} V(t)= & Q(t) \\
V(t)= & -R \dot{Q}(t)
\end{aligned}
$$

By comparing with Equations [8],[9] and [10], we can show that this last system corresponds to a piezomechanical system in which we would have modified the initial short circuit stiffness $K$ to $K+e_{w v}^{T}\left(C_{p}^{S}+C_{n e g}\right)^{-1} e_{w v}$. Thus if $e_{w v}^{T}\left(C_{p}^{S}+C_{n e g}\right)^{-1} e_{w v}$ is a negative matrix, we can easily demonstrate that we could decrease the corresponding short circuit eigen frequencies and also increase the corresponding resistive feedback efficiency as previously demonstrated. To decrease the short circuit stiffness, we also need to use a negative capacitance circuit built by using suitable synthetic circuit. This result corresponds to those obtained by Hagood Von Flotow with a very simple model in (Hagood et al. 1991). In Hagood-Von Flotow work, they introduce an effective stiffness for the shunted piezoelectric laminated composite that can be plotted as in Figure 3. The induced root loci by the resistive part of the shunt with various initial negative capacitance are plotted in Figure 4. One can also materialize a real improvement for stabilizing the considered mode when negative capacitance tends toward $-C_{p}^{T}$ (the piezoelectric capacitance at zero stress) from lower values. For $C_{n e g}$ between $-C_{p}^{T}$ and $-C_{p}^{S}$ the system is unstable as the effective stiffness becomes negative (see Figure 3 ). For values superior to $-C_{p}^{S}$, the negative capacitance part does not introduce any improvement on the resistive induced modal damping.

To optimize such $R C_{n e g}$ circuit one can also use an optimization criterion maximizing the effective piezoelectric coupling coefficient as proposed in Equation [12].

\section{Experimental validation}

\subsection{Experimental protocol}

A steel beam has been used to compare different modeling methodologies (1D Euler-Bernoulli beam and 3D piezelectric model) and to validate the proposed optimization strategy based on the criterion of Equation [12]. The experimental system is described on Figure 5. It stands for a clamped free beam equipped with a glued piezo- 


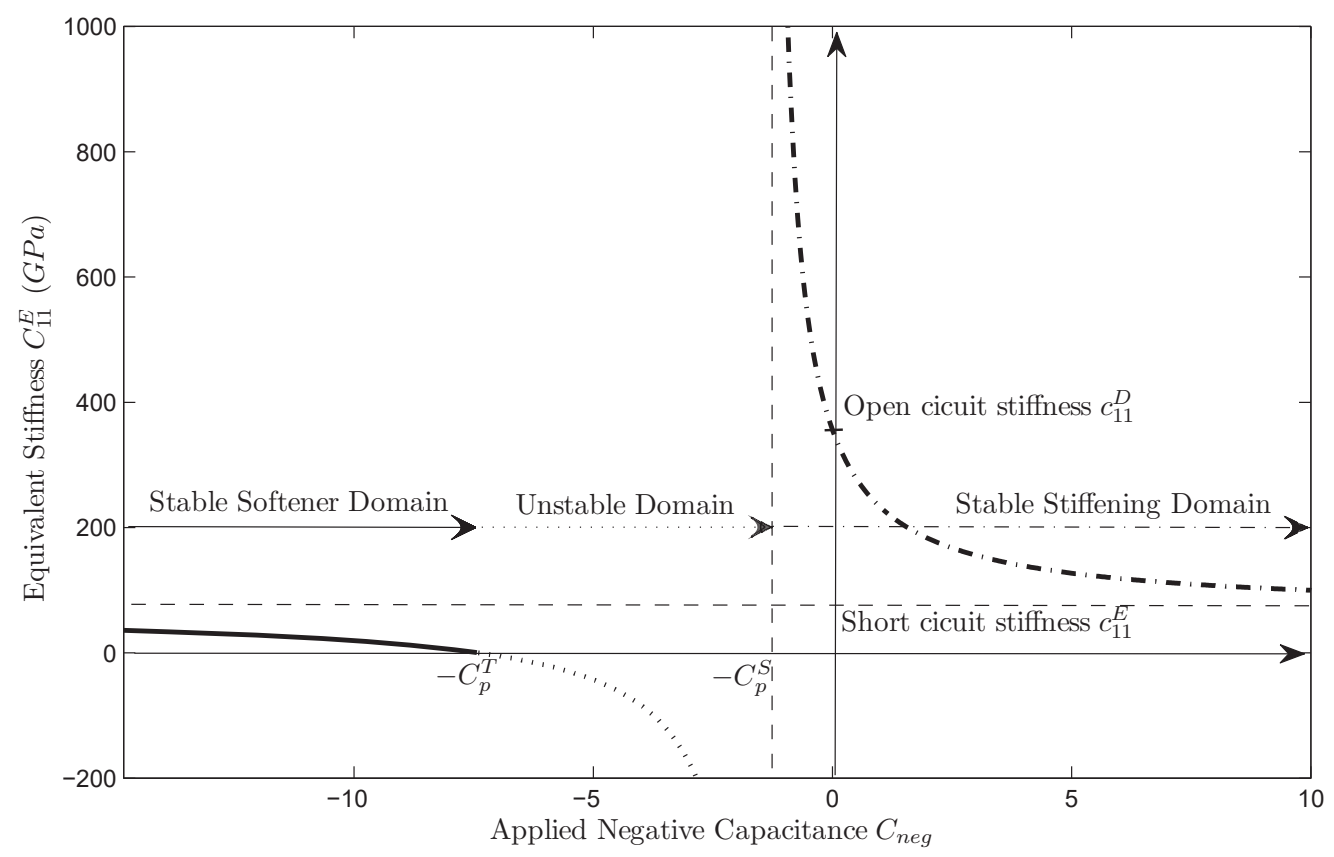

Figure 3. The effective shunted piezoelectric composite stiffness (Hagood et al. 1991) as a function of the connected negative capacitance term

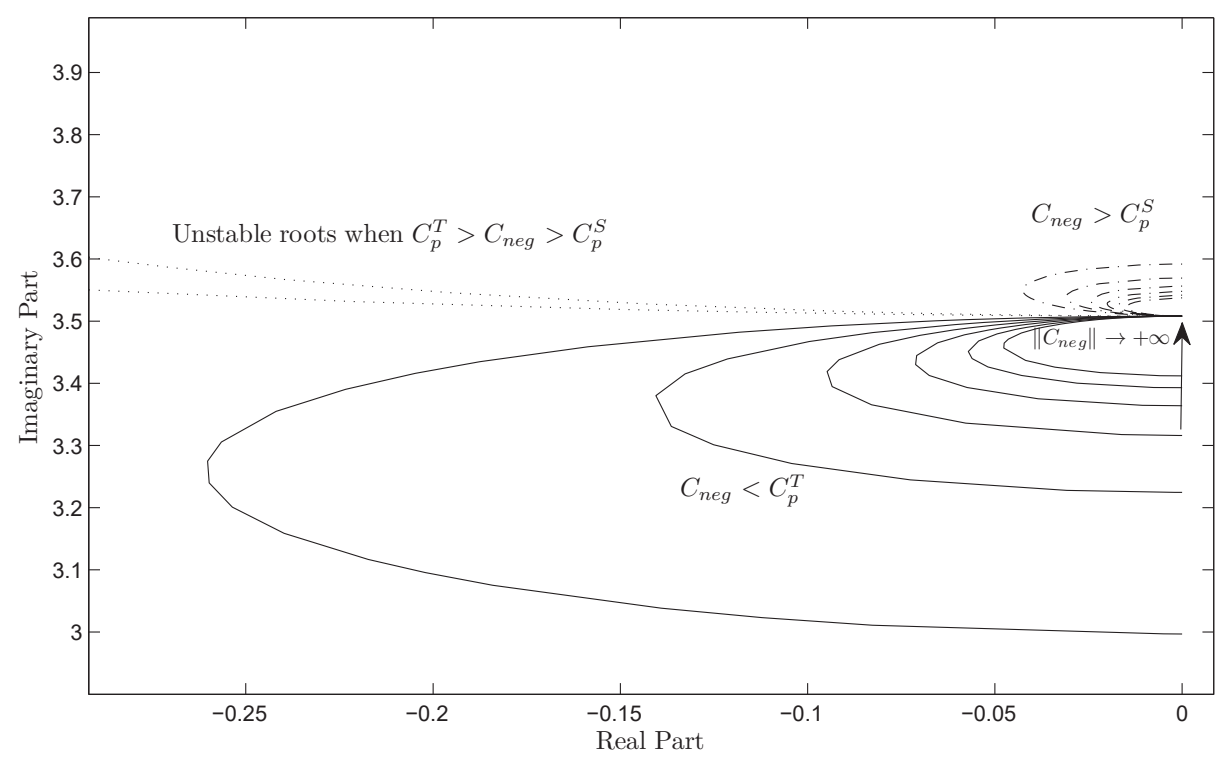

Figure 4. Different $R$ induced mono-modal root loci with different negative capacitance part in the connected shunt

electric patch. For each experimental test, we keep constant the size of the piezoelectric $\left(L_{p}=20 \mathrm{~mm} l_{p}=10 \mathrm{~mm}\right.$ and $e_{p}=0.5 \mathrm{~mm}$ c.f. Figure 1$)$ to be able to compare and evaluate the extra damping as a function of different relative lengths 
( $L=55 / 70 / 90 \mathrm{~mm} \mathrm{l}=10 \mathrm{~mm}$ and $e=1 \mathrm{~mm}$ Figure 1$)$ of the host structure. The piezoelectric element is bonded close to the cantilever beam root $\left(x_{p}=2 \mathrm{~mm}\right)$ to retrieve good damping results for the first bending mode as the strain is then maximum, and also the coupling coefficient. The beam is excited by a contact less electro-

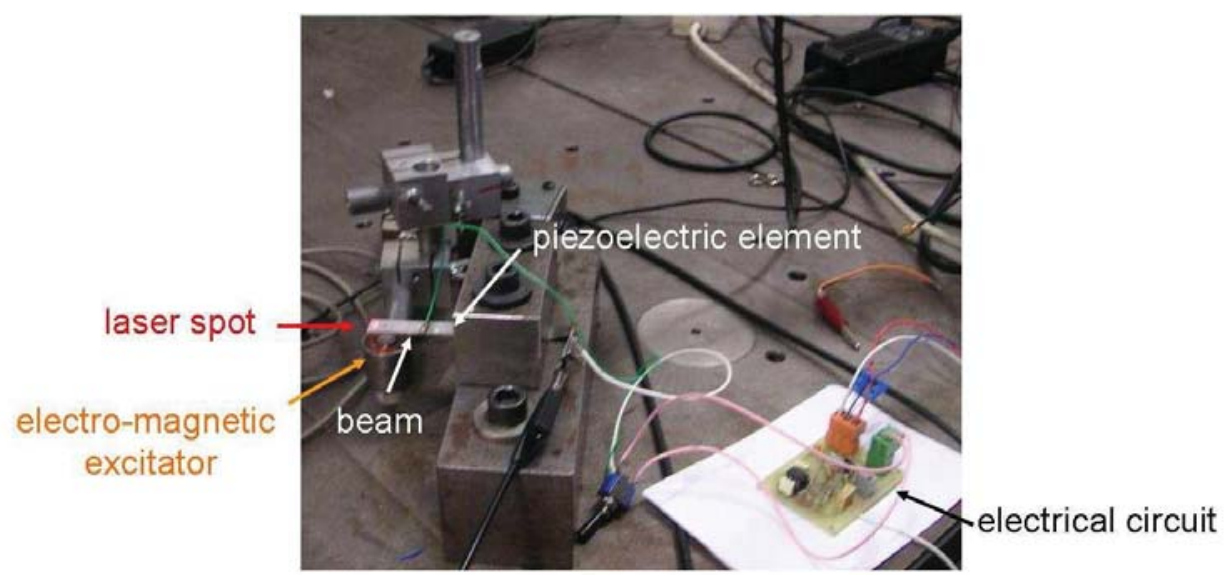

Figure 5. Picture of the experimental assembly

magnetic generator. The damping on the first mode from a white noise is measured by a laser velocimeter and acquired by a PC with Siglab software. Modal analysis technique and Modan ${ }^{\circledR}$ software is used to postprocess eigen frequencies and modal damping ratio by using fitting curve techniques.

\subsection{Resistive shunt}

\subsubsection{Damping influence from the length ratio of piezoelectric patches}

In this part, we consider a simple resistive shunt circuit connected to the embedded piezoelectric patch (Figure 5). The used piezoelectric material is a PZT P1-94 from Saint Gobain Quartz bonded by curing at $\left(80^{\circ} \mathrm{C}\right)$ on the supporting steel beam thanks to a conductive glue (H20E of Epotek). The aim of the experimental tests was to quantify the capability of such a system to damp (or to stabilize) the host beam structure thanks to a resistive shunt varying from 0 (short circuit) to $+\infty$ (open circuit). By this way, we can evaluate the maximum of coupling between the piezoelectric and the beam as a function of different design parameters as explained in Section 2.2.1. So increase the resistance implies an increase of the damping ratio at the beginning and a decrease after passing by an optimum point, while the frequency keeps increasing as described in Figure 2. The measured damping ratio depends on the used resistance as indicated in Figure 2 but also on design parameters. To study sensitivity of maximum induced damping ratio on the relative length between the supporting plate and the used piezoelectric patch and its connexion with our proposed criterion in Equation [12], we have experimentally evaluated for different beam length the short and open-circuit first eigen frequencies of the system, the free structural damping and the maximum of induced resistive damping as well as the obtained peak magnitude attenuations. These results are summarized in Table 1. 
We also note the direct relation between the difference of the short and open-circuit eigen frequencies and the obtained maximum stabilization on the obtained resistive damping or on the peak attenuation. That confirms the possibility to use the proposed criterion (Equation [12]) for optimizing such passive system. Considering our experimental tests, the more efficient system is shown to be the first one with a beam length of $55 \mathrm{~mm}$.

Table 1. Passive Damping Results From Experiments

\begin{tabular}{|c|c|c|c|}
\hline & $55 \mathrm{~mm}$ beam & $70 \mathrm{~mm}$ beam & $90 \mathrm{~mm}$ beam \\
\hline Short-circuit frequency $(\mathrm{Hz})$ & 360.3 & 210.0 & 121.4 \\
Open-circuit frequency $(\mathrm{Hz})$ & 366.5 & 212.7 & 122.7 \\
\hline Structural damping $(\%)$ & -0.1768 & -0.1295 & -0.1376 \\
Maximal R damping $(\%)$ & -0.9764 & -0.744 & -0.654 \\
\hline$\delta$ R damping $(\%)$ & -0.80 & -0.61 & -0.52 \\
$\delta$ Magnitude damping & $-18 \mathrm{~dB}$ & $-13 \mathrm{~dB}$ & $-12 \mathrm{~dB}$ \\
\hline
\end{tabular}

\subsubsection{Damping impact due to piezoelectric material type}

In this second part, let us compare relative piezoelectric material efficiency for stabilizing the supporting beam when a simple resistive shunt circuit is connected. Two different types of piezoelectric material have also been tested during the experimental studies. Keeping the same size of material, we have use PMN-33PT material from TRS Technology in comparison with the previously used PZT P1-94 from Saint Gobin Quartz (Cao, Schmidt, Cao, Rui et Luo 2004). The capabilities of PMN-33PT material for absorbing vibration were already proved in (Rusovici, Dosch et Lesieutre 2002). The PMN-33PT is a single crystal material and is a softer piezoelectric element than PZT that explains the lower eigen frequencies observed on the PMN-33PT equipped beam. It has also less impact on the host behavior and deflection of the beam. Moreover it has also better coupling coefficients. For a $55 \mathrm{~mm}$ beam with embedded PMN33PT connected to resistive shunt, we experimentally measure twice the maximum damping ratio obtained by using a PZT P1-94 transducer. The extra damping $\xi$ on the structure equipped with PMN-33PT reaches about $2 \%$, which corresponds to a peak attenuation of $25 d B$ compared with uncontrolled response (Figure 6).

\subsection{Correlation with theoretical modeling}

The first computation made by using the nominal piezoelectric PZT material characteristics was not correlated with the obtained experimental results. Indeed, the initially used PZT P1-94 had lost a part its polarization during the cure $\left(80^{\circ} \mathrm{C}\right)$ for bonding the element on the supporting steel beam thanks to a conductive glue (H20E of Epotek). We have also updated the material characteristic of the used piezoelectric 


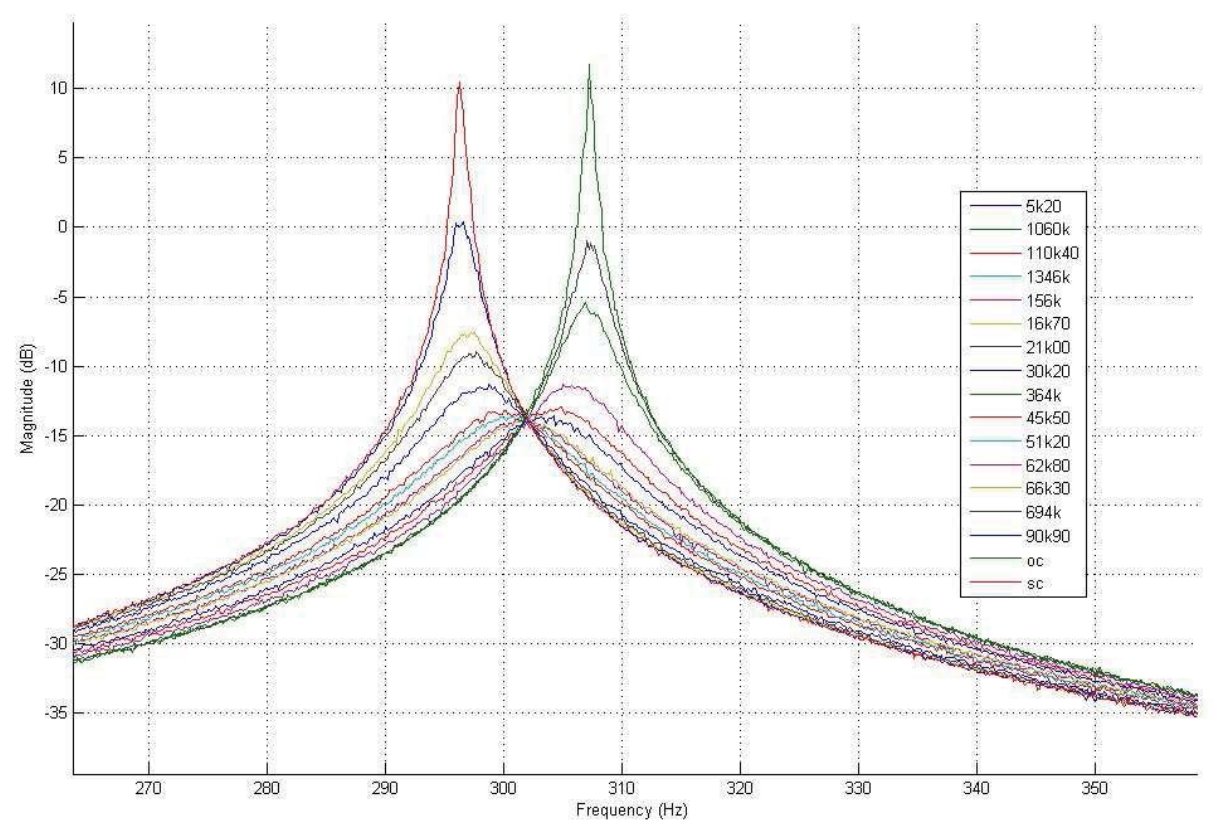

(a)

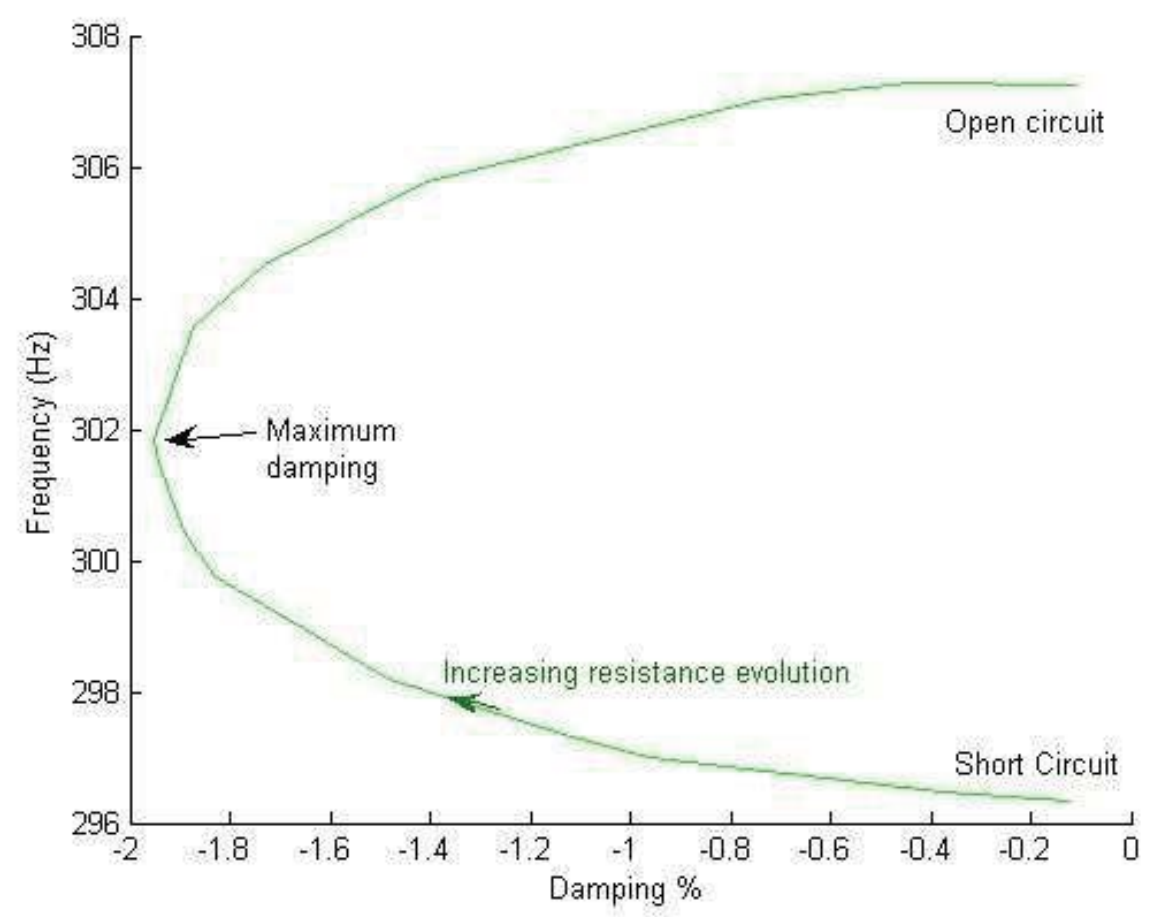

(b)

Figure 6. Mechanical frequency response function (a) and Evans Diagrams (b) of a $55 \mathrm{~mm}$ Beam with a PMN-33PT at different resistive shunt 
by curve fitting techniques and obtained closer results to the ones of Saint Gobain Quartz PZT P1-91. This last material characteristics has been used to perform two different numerical computations of the system's root locus when a resistive shunt is considered. The first computation is based on a standard 1D model as in (Collet et al. 2003, Hac et al. 1993, Tzou et al. 1994b) and the second one on a full 3D models as in (Collet et al. 2008). The obtained results, in term of short and open circuit first natural frequencies, maximum induced damping ratios and corresponding shunt resistance are synthesized in Table 2.

Table 2. Passive damping results from $1 D$ and $3 D$ theory

\begin{tabular}{|c|c|c|c|c|c|c|}
\hline Beam length & \multicolumn{2}{|c|}{$55 \mathrm{~mm}$} & \multicolumn{2}{|c|}{$70 \mathrm{~mm}$} & \multicolumn{2}{|c|}{$90 \mathrm{~mm}$} \\
\hline Model type & $1 \mathrm{D}$ & $3 \mathrm{D}$ & 1D & $3 \mathrm{D}$ & 1D & $3 \mathrm{D}$ \\
\hline $\begin{array}{c}\text { Short-circuit } \\
\text { frequency }(H z)\end{array}$ & 361.0 & 354.9 & 213.9 & 211.0 & 124.0 & 122.7 \\
\hline $\begin{array}{c}\text { Experimental } \\
\text { relative error }(\%)\end{array}$ & 0.194 & -1.50 & 1.86 & 0.48 & 2.1 & 1.07 \\
\hline $\begin{array}{c}\text { Open-circuit } \\
\text { frequency }(H z)\end{array}$ & 367.0 & 361 & 216.9 & 213.9 & 125.4 & 124.1 \\
\hline $\begin{array}{l}\text { Initial damping } \\
\text { ratio }(\%)\end{array}$ & 0.18 & 0.18 & 0.13 & 0.13 & 0.14 & 0.14 \\
\hline $\begin{array}{c}\text { Maximal R } \\
\text { damping (\%) }\end{array}$ & -0.995 & -1.00 & -0.832 & -0.811 & -0.655 & -0.666 \\
\hline $\begin{array}{c}\text { Experimental } \\
\text { relative error }(\%)\end{array}$ & 1.90 & 2.4 & 11.8 & 9.0 & 0.153 & 1.83 \\
\hline
\end{tabular}

The relative error in Table 2 on the expected theoretically damping is rather small. We pointed out that most of the frequencies are overestimated by our models. That can be explained by the fact that the used glue is not numerically taken into account. In consequence we observe that the glue may add some mass on the structure but seems to have a poor impact on the damping ratio. There is not any noticeable difference between $1 \mathrm{D}$ and $3 \mathrm{D}$ modeling approaches for evaluating the accessible resistive shunt performances to stabilize the first mode of the beam. Nevertheless, we can point out some larger differences in computing the first natural frequencies especially for the short beam length (where the piezoelectric patch covers the larger relative surface of the beam).

\subsection{Negative capacitance shunt}

As presented in Section 2.2.2, we can largely improve damping capability of the resistive shunt circuit by adding a negative capacitance in the circuit. Such active components are synthesized by an electronic circuit citeA.J.Fleming2000 such the one presented in Figure 7. The device works as an equivalent capacity $C_{e q}=\frac{R_{7}+\gamma R_{8}}{(1-\gamma) R_{8}} C_{1}$ 
for frequencies above $\frac{1}{R_{3} C}$. It can be tuned thanks to $\gamma$ through the potentiometer $R_{8}$ which is variable from 0 to $20 k \Omega$. The observed breaks on the root locus lines on diagram (Figure 8) correspond to the upper limit of available resistance range. The considered system is the steel beam of dimension $L=55 \mathrm{~mm} \mathrm{l}=10 \mathrm{~mm}$ and $e=1 \mathrm{~mm}$ figure equipped with a previously used P1-94 PZT patch $\left(L_{p}=20 \mathrm{~mm}\right.$ $l_{p}=10 \mathrm{~mm}$ and $e_{p}=0.5 \mathrm{~mm}$ )as depicted on Figure 1. Different measurements

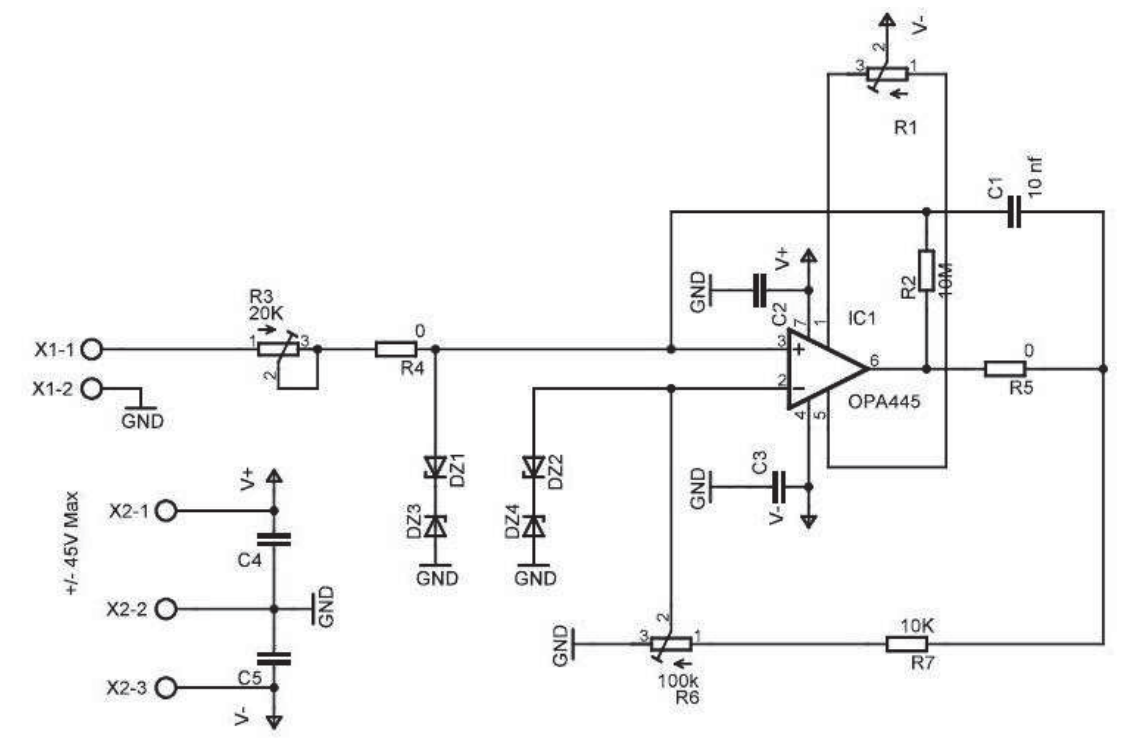

Figure 7. Electronic negative capacity diagram

have been done for a set of negative capacitance and resistance values. For each used equivalent negative capacity, the resistive depending Evans diagrams are plotted on Figure 8. The amplitude of the mechanical Frequency Response Functions between the applied force and the collocated acceleration measurement are also presented for different values of the shunt resistance and a implemented negative capacitance of $-16 n F$. Thanks to this system, we can observe on root loci in Figure 8 a very high induced damping effect. With the same PZT patch shunted by the best resistance (see Table 1), we gain more than $4 \%$ of damping ratio and $30 d B$ attenuation in magnitude on the first mode, just before that the system instability occurs. Indeed the system remains stable for negative capacities below the capacity at contant stress $-C_{p}^{T}$ as show in (Hagood et al. 1991, Collet, Cunefare et Ichchou 2009). This instability is visible on the theroetical bode diagram in red on Figure 4 obtained for a capacity just above $-C_{p}^{T}$. We have also validated by experimental measurements the theoretical behavior pointed out in Section 2.2.2.

\section{Optimization of the location of $\mathbf{R}$ shunted piezoelectric patches on a plate}

\subsection{Numerical validation of the proposed criterion to optimize the induced modal damping ration by a $R$ shunted piezoelectric patch}

Thanks to the criterion described in Equation [12], it is possible to study the ideal localization or size of $\mathrm{R}$ shunted piezoelectric to damp specific modes. Indeed for 


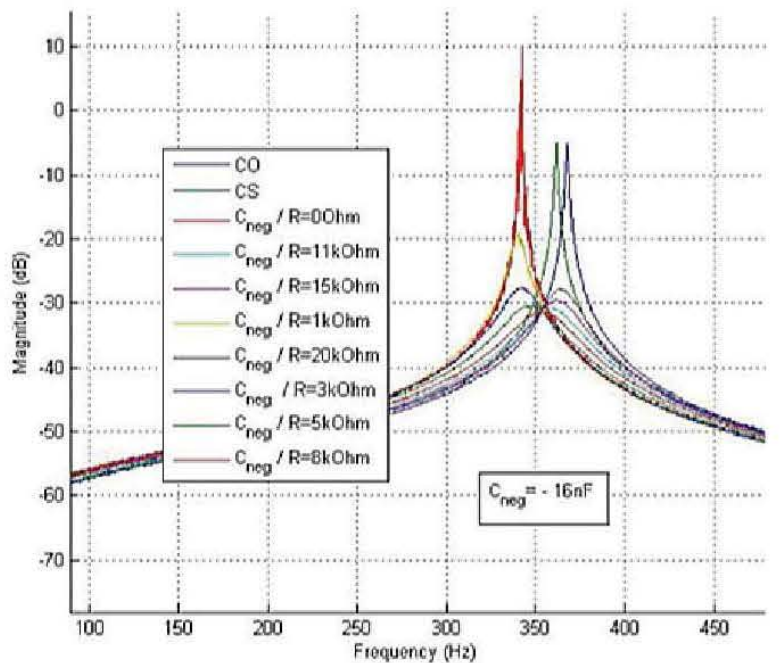

(a)

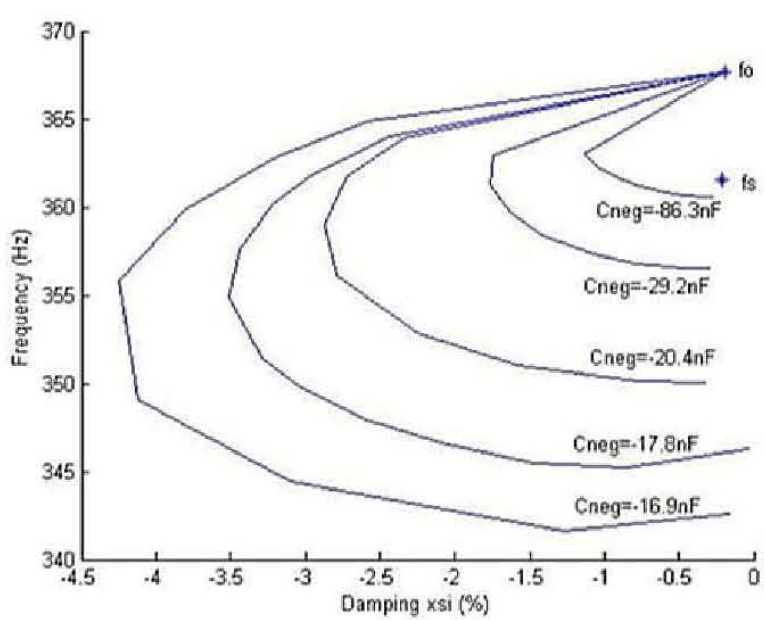

(b)

Figure 8. Mechanical frequency response function (a) and Evans Diagrams (b) of a $55 \mathrm{~mm}$ Beam with a PZT at different negative capacity and resistive shunt

each eigen frequency, the criterion, which is based on the difference of eigenvalues at short and open circuit (Equation [12]), allows us fast optimization calculations. This calculation does not involve the electrical shunt type which needs to be optimized separately mode per mode. The optimal shunt parameters depend on the chosen mode while the accessible efficiency depends only on the electromechanical coupling. In this methodology, the computation of only two particular eigen frequencies are then required to optimize the geometry of the piezoelectric set-up.

To validate the capacity of such a simple approach to determine the best location of piezoelectric patches in order to damp specific modes, let us consider a very simple mechanical example. The chosen system is still the same $55 \mathrm{~mm}$ long steel beam equipped with some PMN-33PT piezoelectric patches. The used numerical model corresponds to a 3D condensed model as described in (Collet et al. 2008). All necessary procedures were developed with Matlab® using the matrix data (stiffness/mass) from the Comsol Multiphysics 3.3 @software.

The first numerical tests aim at showing the validity of the proposed criterion (Equation [12]) for optimizing the piezoelectric's length for inducing the best modal damping ratios when a resistive shunt is connected. The used system is represented on Figure 1 with a beam length $L=55 \mathrm{~mm}$ and a PMN-Pt piezoelectric patch. We also study the evolution of function $\Theta_{i}\left(L_{p}, x_{p}=x_{p o}, e=e_{o}\right)$ depending only on the considered piezoelectric length $L_{p}$ and compare it with the obtained maximal modal damping ratios when a resistance shunt is connected to the patch. Figure 10 presents the maximum modal damping ratios for the first four modes as functions of the length ratio between the piezoelectric patch and the beam while Figure 9 shows the corresponding expression of the criteria $\Theta_{i}\left(L_{p}, x_{p}=x_{p o}, e=e_{o}\right)$ (Equation [12]). The extrema summarized in Table 3 are totally equivalent for both numerical tests plotted 
on Figures 9 and 10. We also validate the correlation between the used criterion and the efficiency of the R shunted system to stabilize the cantilever beam.

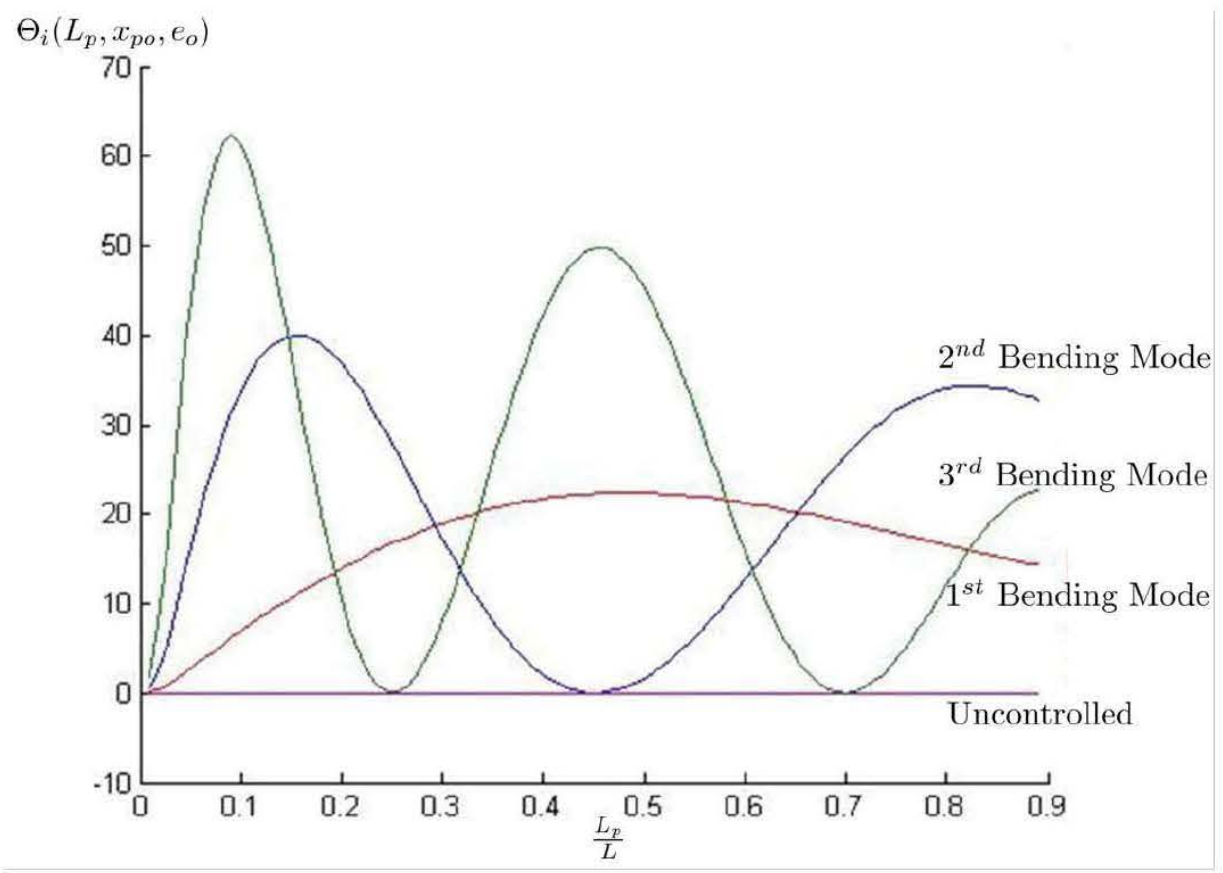

Figure 9. Evaluation of function $\Theta_{i}\left(L_{p}, x_{p}=x_{p o}, e=e_{o}\right)$ on the first four modes as function of the length ratio between the piezoelectric patch and the beam

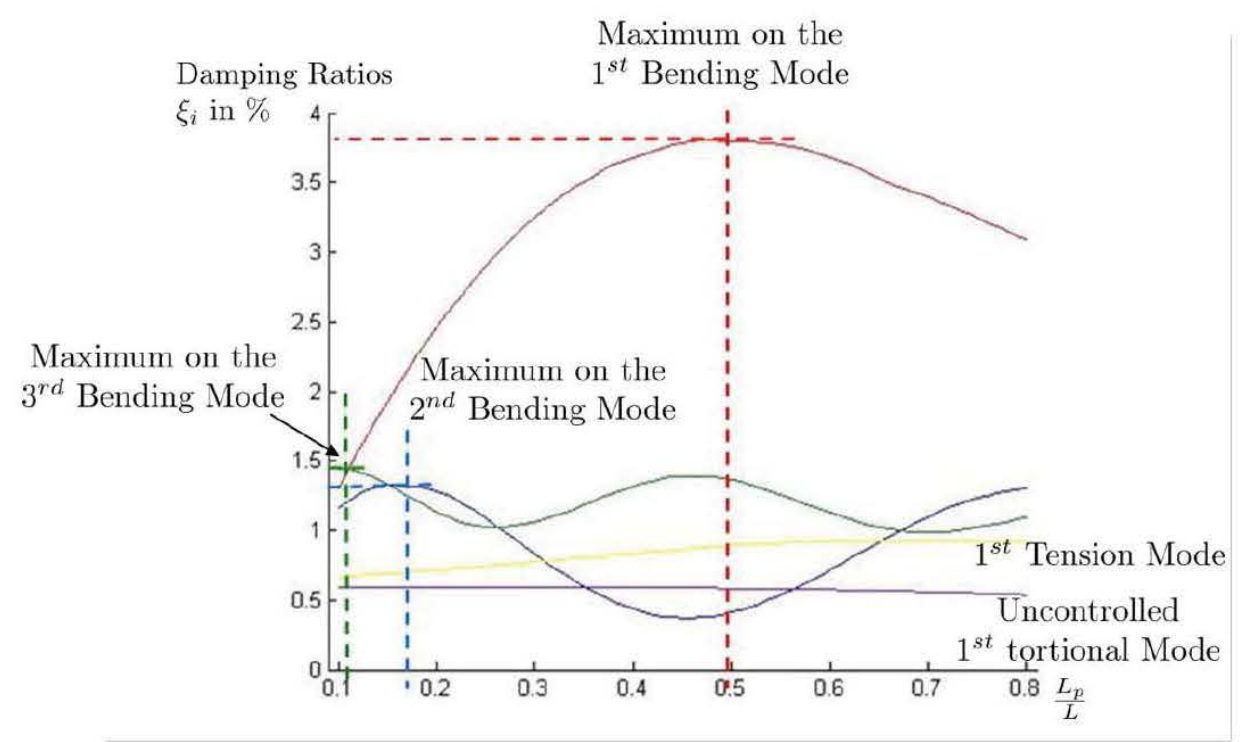

Figure 10. Maximal modal damping ratios of the first four modes obtained with a resistive shunt as a function of the length ratio between the piezoelectric patch and the beam

It is also visible that the efficiency of the piezoelectric depends on its length and, of course, on the considered mode. So, to each mode corresponds an ideal length of the piezoelectric as shown in Table 3 . We can note that efficiency to damp flexural 
modes is very important compared to the one to damp torsional ones. This is due to the low coupling coefficients of the piezoelectric material on shear strain, which induces a lack of controllability of our system on these modes.

To optimize a set of $\mathrm{R}$ shunted piezoelectric patches to damp several modes, our criterion needs to allow a comparison between several induced modal damping ratios. As shown in Figures 9 and 10, it is not the case when simply using $\Theta_{i}\left(L_{p}, x_{p}, e\right)$. To introduce the suitable normalization we propose to modify the previously used criterion (Equation [12]) for :

$$
\bar{\Theta}_{i}\left(L_{p}, x_{p}, e\right)=\frac{\omega_{o c_{i}}^{2}-\omega_{s c_{i}}^{2}}{\omega_{i}^{2}}
$$

where $\omega_{i}$ stands for the corresponding eigenfrequency of the mechanical system without any piezoelectric patches. By assuming low piezoelectric coupling effect inducing small differences between each set of computed modes, one can precisely associate this mode to the corresponding pair of electromechanical ones. In other cases, one need to associate each mode by using a dedicated Modal Assurance Criterion (MAC) for example.

Table 3. Modal Optimum of the Length Ratio between the Piezoelectric and the Beam

\begin{tabular}{|c|c|c|c|}
\hline Flexural Mode to optimize & 1 st & 2nd & 3rd \\
\hline Piezo/Beam Length Ratio & $\approx 1 / 2$ & $\approx 1 / 6$ & $\approx 1 / 10$ \\
\hline
\end{tabular}

The second numerical tests aims at showing the sensibility of the used criterion for determining the optimal location of a $\mathrm{R}$ shunted piezoelectric patch to obtain the maximum modal damping. Moving a constant sized piezoelectric (20 $\mathrm{mm}$ in length) on the whole length of the structure ( $70 \mathrm{~mm}$ long cantilever beam), it is possible to observe in Figure 11 that the localization impacts on the reachable maximal modal damping ratios. In the case of the first bending mode, the best position for the piezoelectric element remains to be the closest to the clamped side of the beam. For the second bending mode, the ideal position gets closer to the middle of the beam. Regarding the third bending mode, two positions seem damping efficient. Those are located at each end of the beam. As in the previous study, the efficiency of the piezoelectric for the torsion and edgewise modes, which is not working in its privileged directions, remains very poor.

All those results are verified by the computation of the proposed criterion $\Theta_{i}\left(L_{p}, x_{p}, e=e_{o}\right)$ as shown in Figure 12. It is possible to conclude on the possibility to build an efficient numerical design procedure for optimizing a $\mathrm{R}$ shunted piezoelectric system to induce large modal damping ratios thanks to this criterion. 


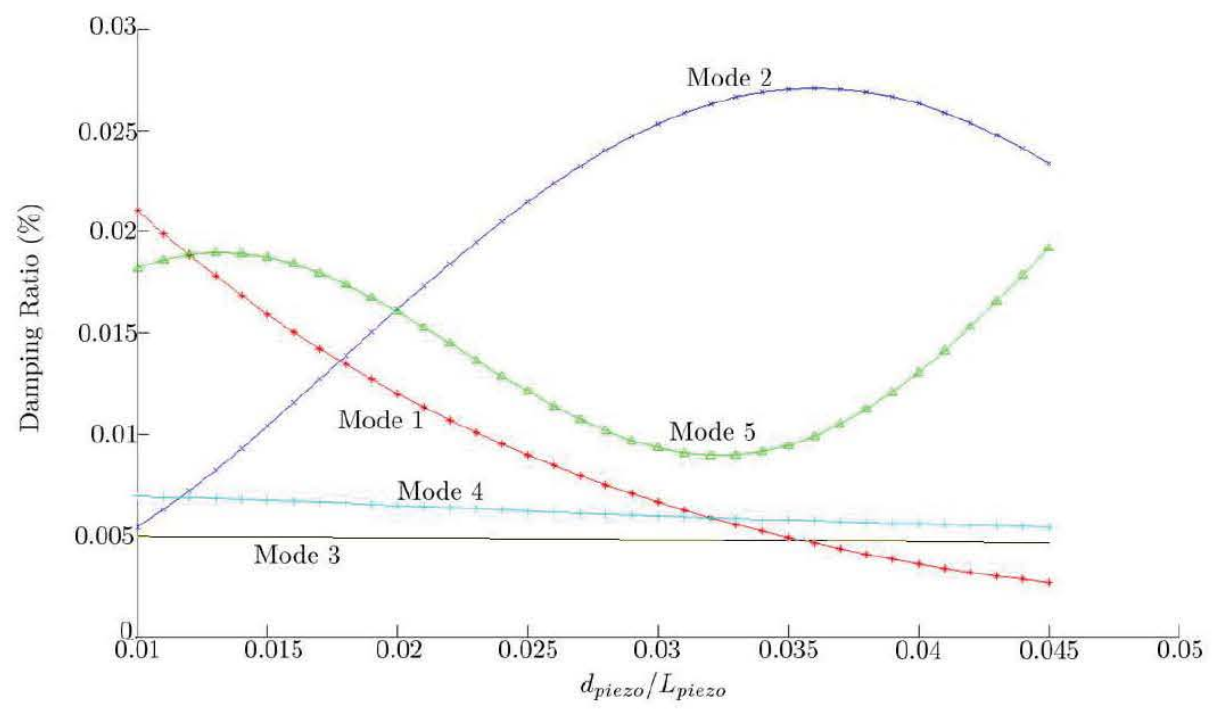

Figure 11. Maximal damping from a resistive shunt as a function of the transducer distance to the cantilever beam root

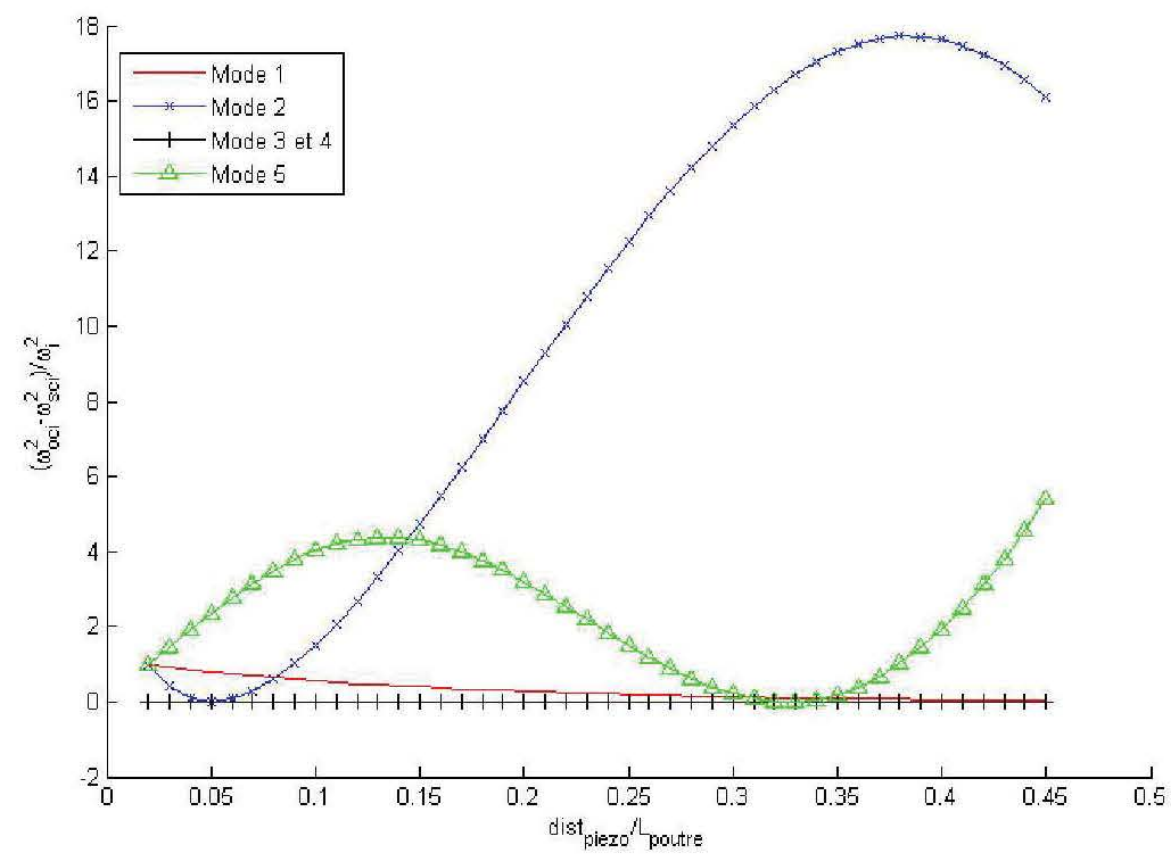

Figure 12. Optimization criterion value [16] as a function of the transducer distance to the cantilever beam root

\subsection{System description and constrain specifications}

Validated in the previous section, the criterion (Equation [16]) is used to search the optimal configuration for stabilizing a plate structure by shunted piezoelectrics 
layers. The main aims are also to validate the criteria for optimizing induced damping ratios on several modes and the proposed numerical methodology. For doing such an optimization, we add additional constraints on our problem :

- the number of piezoelectric elements are limited.

- all piezoelectrics possess the same size and are made from the same material. Only the localization will be optimized.

- the piezoelectrics are not electrically linked all together.

- the electrical circuit are constituted by only resistive elements.

Several modes can be damped thanks to resistive shunt circuits connected to different piezoelectric patches. The control device has also to be ruled for focusing efficiency on specified modes. It is not only the electrical circuit but also the localizations of the piezoelectric patches which has to be optimized. The piezoelectric material characteristics are also fundamental. Indeed their coupling coefficients play an important role as previously mentioned. Playing with the material, size and localization of the transducers, it is possible to focus the system efficiency for damping specific modes.

The considered system is a clamped free aluminum plate of dimension $L_{a} \times l_{a} \times$ $e_{a}=140 \times 50 \times 1 \mathrm{~mm}^{3}$, in which to control the first three modes: the first bending mode, $F 1$, (around $50 \mathrm{~Hz}$ ) and its second (first torsion $T 1$ ) and third (second bending F2) modes around $300 \mathrm{~Hz}$.

In order to control these three first modes, seven piezoelectrical transducers are placed on the plate. Each of them are $2 \times 1 \times 0.5 \mathrm{~mm}^{3}$ sized. The used material is PMN-PT because of its high inherent coupling coefficient inducing a high capability to passively damp vibration through a simple resistive shunt circuit.

\subsection{Multi-modal optimization of $R$-shunted piezoelectric patches on a plate}

\subsubsection{Modeling}

The plate model is obtained from the Mindlin theory and each piezelectric patches are modelled by using 3D piezoelectric bricks element connected to the plate by imposing continuity between the 3D displacements and interface movements coming from Mindlin cinematic. The piezoelectric boundary conditions are to impose zero charge displacement normal to the lateral faces, a bottom ground electrod and a top electrode (having a constant potential) connected to open and close circuit for computing short circuit and open circuit eigen frequencies.

\subsubsection{Parametrization}

The piezoelectrics can be localized on the plate on the $x y$ plane and oriented from $(O x)$ axis with an angle $\theta$ as depicted on Figure 13. The optimization algorithm is constrained by conditions on the free space between piezoelectric layers. These 
elements must not obviously exit the plate and stay away from the clamped zone with a distance of $\delta_{a}=1 \mathrm{~mm}$ but they cannot also have a non null intersection.

To stay inside the plate, the center coordinates of one piezoelectric $\left(x_{p}, y_{p}, \theta_{p}\right)$ can operate in the rectangular domain of the plate centered on points of coordinates $\left(x_{a}, y_{a}\right)$ following the constrains expressions given in Equation [19] (Figure 13) :

$$
\begin{aligned}
x_{a}+\delta_{a}-\frac{L a}{2}+\frac{L p}{2} \leq x_{p} & \leq x_{a}+\frac{L a}{2}-\frac{L p}{2} \\
y_{a}-\frac{l a}{2}+\frac{l p}{2} \leq y_{p} & \leq y_{a}+\frac{l a}{2}-\frac{l p}{2} \\
-\frac{\pi}{2} \leq \theta_{p} & <\frac{\pi}{2}
\end{aligned}
$$

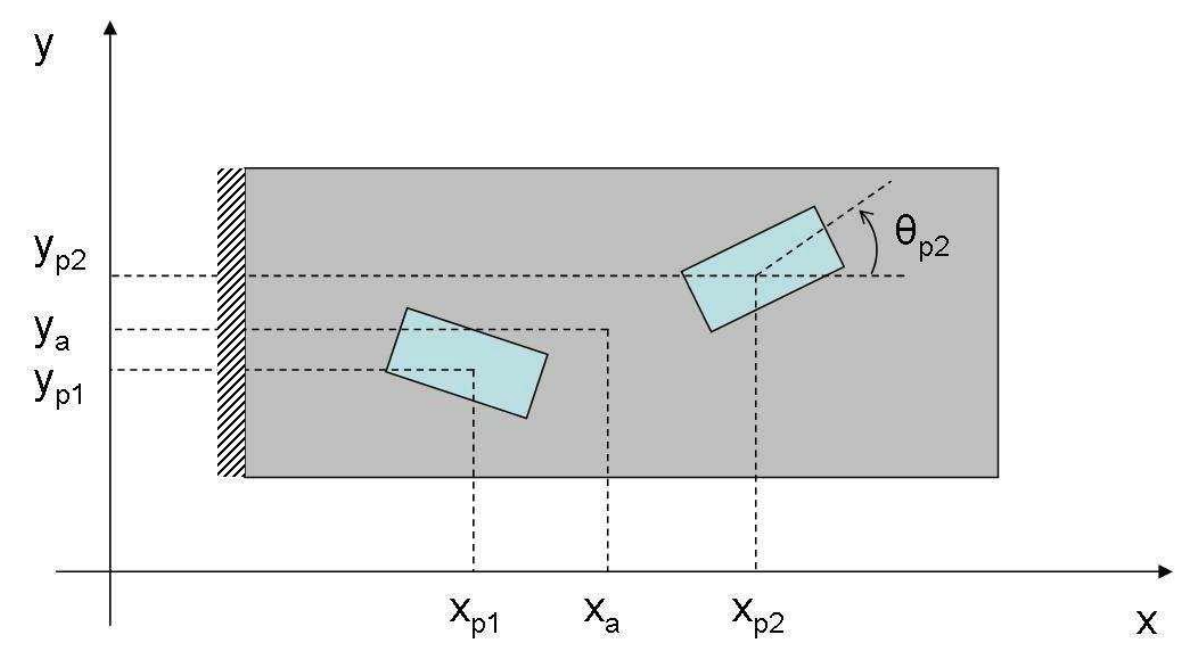

Figure 13. Parameters of piezoelectrics disposed on the plate

\subsubsection{Multi-modal criteria in the case of several piezoelectrics}

For optimizing damping effect on a specific mode $i$, we use the criterion given in Equation [20]. To take into account constrains of null intersection between each piezoelectric covered domains, we introduce, for each piezoelectric, its minimal distance with its neighbors ones called $d_{p}$. The unimodal used criterion is also given in Equation [20]. It is based on the computation of the difference between open and short circuit eigenvalues $\Theta_{i}$ weighted by an hyperbolic tangent function of the minimal distance constrain. This distance is chosen to $1 \mathrm{~mm}$ that induce a rapid penalization of the criterion when the piezoelectric distance goes below $1 \mathrm{~mm}$. The new function to optimize is also noted $\Gamma$ and expressed as in Equation [20].

$$
\Gamma_{i}\left(x_{p}, y_{p}, \theta_{p}\right)=-\bar{\Theta}_{i}\left(x_{p}, y_{p}, \theta_{p}\right) \cdot \tanh \left(\frac{\min \left(d_{p}\left(x_{p}, y_{p}, \theta_{p}\right)\right)}{10^{-3}}\right)
$$


The use of several piezoelectrics can lead to damp several modes. For an optimization on $[m]$ distinct modes, the relationship in Equation [20] becomes Equation [21].

$$
\Gamma_{[m]}\left(x_{p}, y_{p}, \theta_{p}\right)=-\left(\sum_{i=[m]} \bar{\Theta}_{i}\left(x_{p}, y_{p}, \theta_{p}\right)\right) \cdot \tanh \left(\frac{\min \left(d_{p}\left(x_{p}, y_{p}, \theta_{p}\right)\right)}{10^{-3}}\right)
$$

The used optimization algorithm is a standard 'Simplex' procedure (Lagarias, Reeds, Wright et Wright 1998).

\subsubsection{Piezoelectric location optimization}

Based on the multi-modal criteria given in Equation [21], we have optimized the location of seven rectangular piezoelectric patches for stabilizing the first three modes of the system $(m=3)$. The used numerical method is the simplex algorithm of Matlab® based on computations with Comsol Multiphisic ${ }^{\circledR}$ of the first three pairs of short and open circuit eigenfrequencies of the coupled system. The initial conditions has been carefully chosen to avoid to obtain one of the numerous local optima. For this end, each initial patch has been localized near one of maximum modal strain energy of the first three modes. The obtained location is depicted on Figure 14.

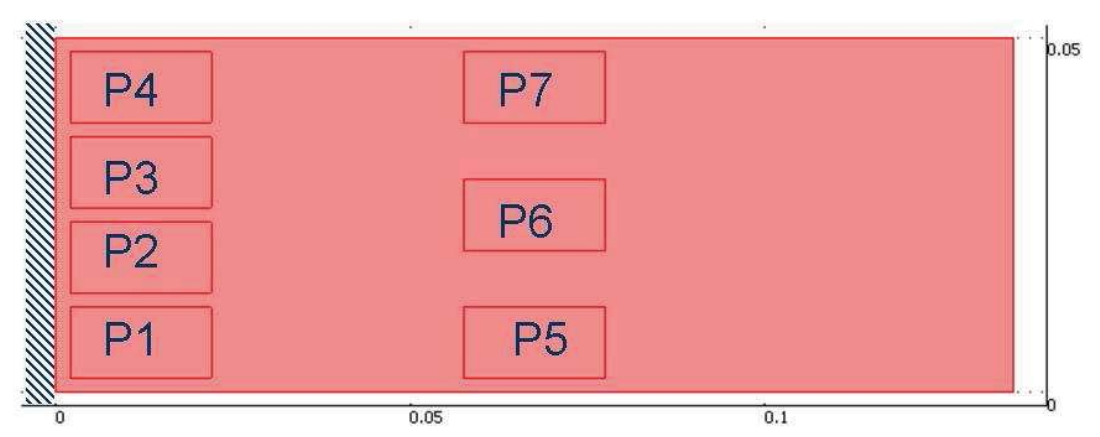

Figure 14. Optimal locations of the seven piezoelectric onto the plate

As shown on Figure 14, one can underline the symmetry of the obtained optimal system. The optimization procedure leads also to locate numerous patches near the clamped edge where the first flexural and torsional modes induce a maximum stress. The other patches are located in order to increase modal efficiency the higher order modes.

\subsection{Experimental results}

After determining the ideal position of the piezoelectric patches onto the plate, the optimal configuration was tested experimentally. The cantilever plate is placed between jaws as in Figure 15. The tightening has to be realized properly to prevent the risk of complex modes appearing. To do so, some thin copper plates had been 
added in between to lead to a better cohesion. The whole assembly is composed by a contact-less magnetic excitation source placed below the plate and by a laser vibrometer pointing on the left free end point collocated with the force source.

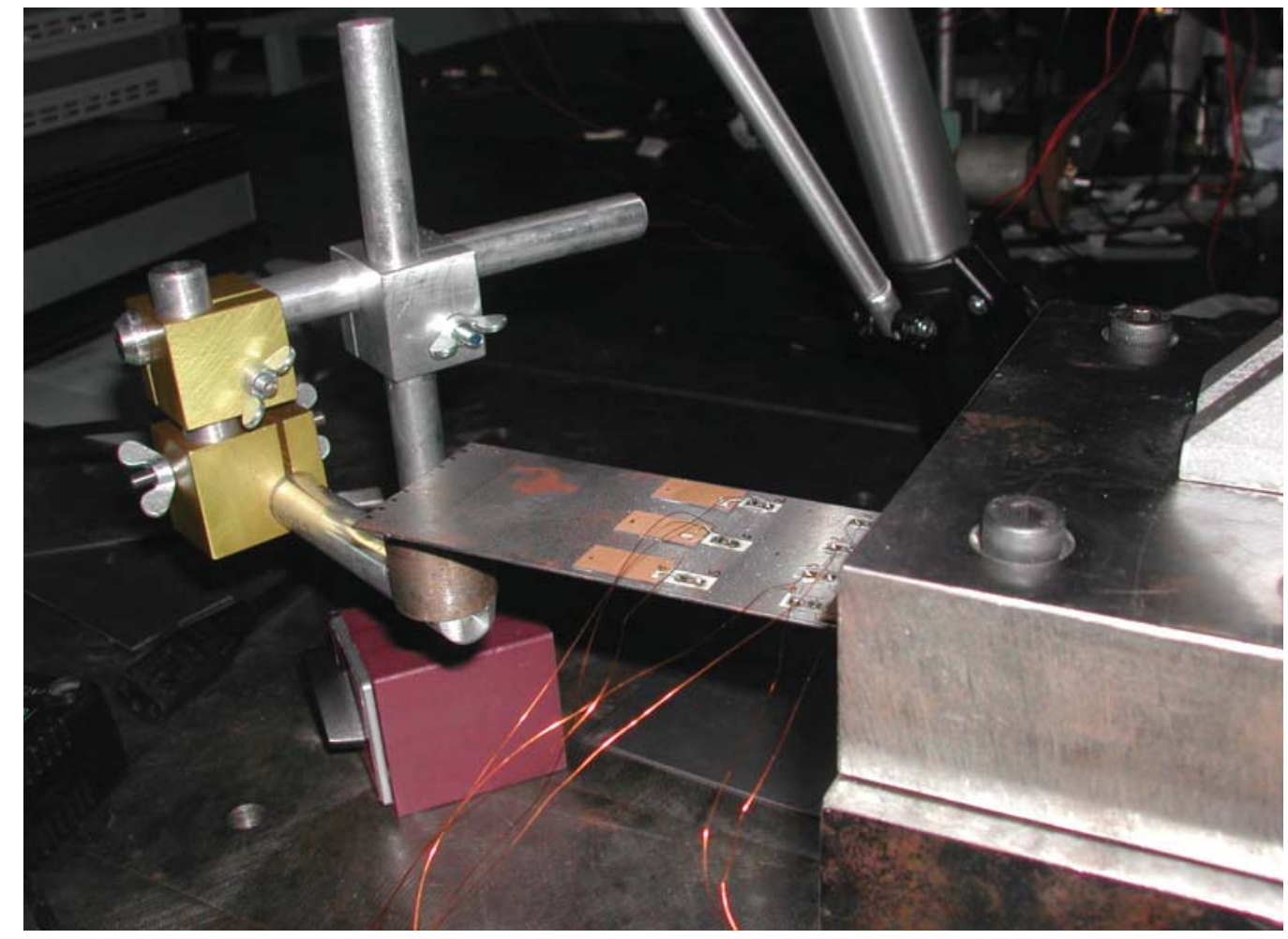

Figure 15. Plate equipped with piezoelectric transducers

Each piezoelectric patch $p$ is linked to a potentiometer $R_{p}$. The tuning of the resistive components is made depending the associated mode to damp. The optimization of each applied resistance on each patch is made by dedicating each patch to damp only one mode depending on its best effective coupling coefficient given by the optimization algorithm. From Figure 14, the piezoelectric patches $P 1$ and $P 4$, placed against the clamping and toward the edges of the plate are used to control the first torsion mode T1, while the piezoelectric patches $P 2$ et $P 3$ situated in between the first two are chosen to damp the first bending mode F1. The pieoelectric patches $P 5, P 6$ and $P 7$ located at the center of the plate are tuned for the second bending mode F2. Each resistance is firstly tuned to obtain individually the best effect on each dedicated modes. The optimization is made by imposing $R_{p}=\frac{1}{C_{p} \omega_{j}}$, where $p$ denote the piezoelectric patch number and $j$ the targeted mode number. This value corresponds to the best impedance matching at the resonance frequency. The resistive circuit is made by a serial of two potentiometers with a different sensibility. The smaller one is used to refine the tuned resistance value. The total accessible range correspond to a resistive control from 0 to $2 \mathrm{M} \Omega$. A three position switch, in each circuit, allows the possibility to connect each piezoelectric in open or short-circuit or to the shunt resistance.

The theoretical unconstrained capacity of the piezoelectric is evaluated to $6 n F$ for a the used PMN-PT material and dimensions $\left(C_{p}=\frac{A_{p} \varepsilon_{33}}{e_{p}}\right.$, with $A_{p}$ the area and $e_{p}$ the thickness of the piezoelectric). Each of them has been measured by a programmable 
RLC-meter while these are already stuck on the structure. The optimized values of the resistance are also ruled as function of this experimental values as mentioned in Table 4.

To complete this first multi modal implementation, a second resistance tuning is made to focus the system to specifically damp the second and the third modes (F2 and T1). In this case, the piezoelectric resistive shunts of patches $P 2$ and $P 3$ are ruled by using resistance values given in Table 4 to damp mode F2 in spite of initially targeted mode F1.

Table 4. Optimal Values of the Resistance Depending on their Effective Electrical Capacity and the Mode to Damp

\begin{tabular}{|c|c|c|c|c|c|c|c|}
\hline Piezoelectric \# & 1 & 2 & 3 & 4 & 5 & 6 & 7 \\
\hline Capacity $C_{p}(\mathrm{nF})$ & 6.48 & 6.06 & 5.82 & 6.29 & 6.41 & 6.75 & 6.26 \\
\hline $\begin{array}{c}\text { Optimal Resistance for } \\
\text { Mode F1 }(\mathrm{k} \Omega)\end{array}$ & $*$ & 536 & 558 & $*$ & $*$ & $*$ & $*$ \\
$\begin{array}{c}\text { Optimal Resistance for } \\
\text { Mode F2 }(\mathrm{k} \Omega)\end{array}$ & $*$ & 90 & 94 & $*$ & 85 & 80 & 87 \\
$\begin{array}{c}\text { Optimal Resistance for } \\
\text { Mode T1 }(\mathrm{k} \Omega)\end{array}$ & 85 & $*$ & $*$ & 87 & $*$ & $*$ & $*$ \\
\hline
\end{tabular}

Table 5. Experimental Results From the FRFs

\begin{tabular}{|c|c|c|c|c|}
\hline Damping (\%) & Short-circuit & $\begin{array}{c}\text { Optimized } \\
\text { Circuit } \\
\text { for Modes F1, } \\
\text { F2 and T1 }\end{array}$ & $\begin{array}{c}\text { Optimized } \\
\text { Circuit } \\
\text { for Modes F2 } \\
\text { and T1 }\end{array}$ & Open Circuit \\
\hline Mode F1 & 0.59 & 1.60 & 1.08 & 0.59 \\
Mode F2 & 0.13 & 0.27 & 0.29 & 0.12 \\
Mode T1 & 0.17 & 1.09 & 1.34 & 0.17 \\
Mode T2 & 0.09 & 0.18 & 0.24 & 0.09 \\
Mode F3 & 0.06 & 0.18 & 0.19 & 0.06 \\
\hline
\end{tabular}

The obtained damping ratios in Table 5 show up a large efficiency of the proposed two passive systems for damping the first three modes of the plate. The damping brought to the first mode is $0.5 \%$ at minimum but can reach $1 \%$ at maximum (which corresponds to $6 \mathrm{~dB}$ with two piezeoelectrics). The system reduces the second mode by $7 \mathrm{~dB}(+0.14 \%$ of damping) and the third mode by $15 \mathrm{~dB}(+0.92 \%)$. The corresponding Frequency Response Fonctions are plotted in Figure 16 As expected, the specialization of each piezoelectric patch to damp a specific mode plays an important role on the damping efficiency. The first type of tuning damps a lot better the first bending mode 


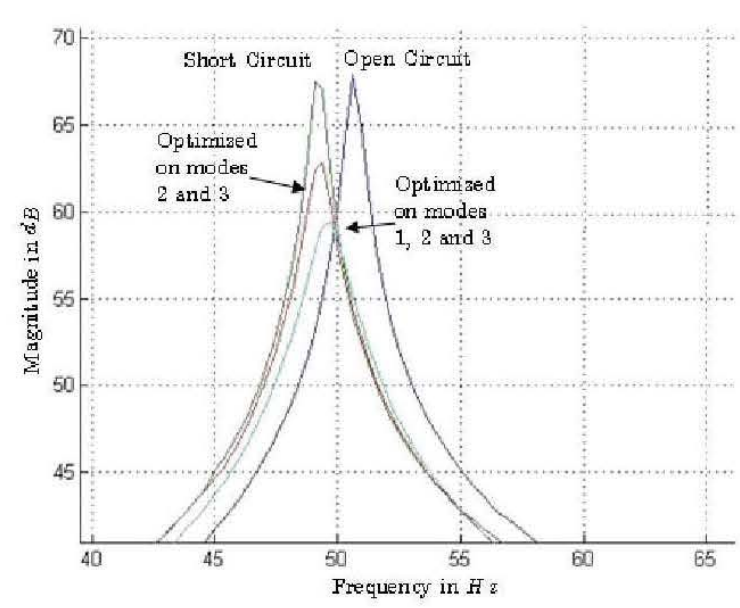

(a)

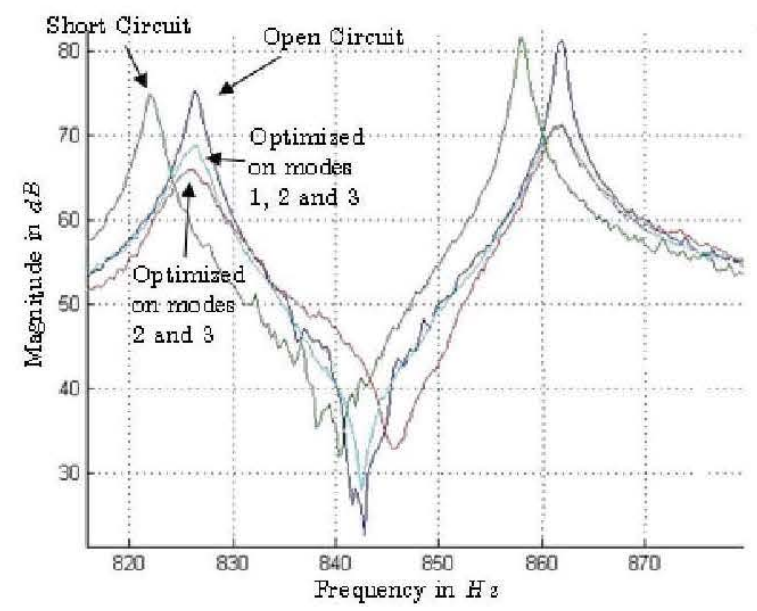

(c)

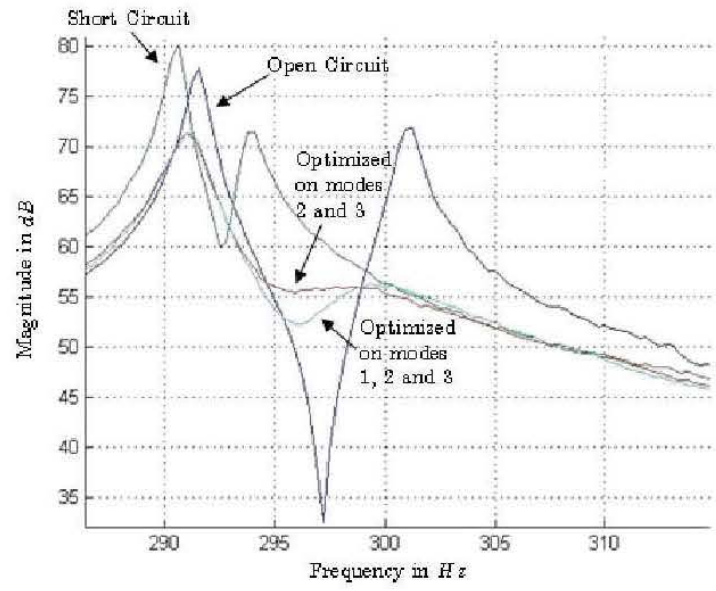

(b)

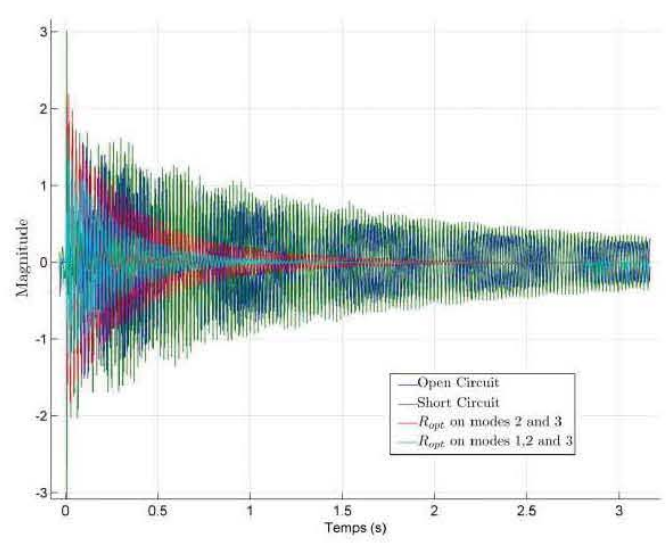

(d)

Figure 16. Frequency response functions and impact responses in open/short circuits and resistive circuits optimized for Modes 2 and 3 or Modes 1,2 and 3 a) around the first mode, $b$ ) around the second and third modes, $c$ ) around the fourth and fifth modes in open/short circuits and for both resistance configurations d) Impact Response

while the mode 2 and 3 are still well damped. It is interesting to note that the following modes, as the torsion mode $\mathrm{T} 2$ and bending mode $\mathrm{F} 3$, are also affected by the passive control. In the second type of tuning, damping effect on modes 2 and 3 are improved. The unoptimized following modes are also impacted since the used resistances are lower that corresponds to the best tuned values for these modes. The response of the plate to an impulse can be also observed in Figure 16.d. Thanks to the resistive shunts, the stabilization rate is improved. The passive control presented here is visibly very efficient even though the resistances have not been precisely tuned : the used optimization rules suppose no or low interactions between the piezoelectric layers and their electrical circuits. However tuning the resistances induces a modification of the 
system's stiffness and so, of its eigenvalues. It means that the tuning is not anymore appropriate as the optimal resistance depends on the frequencies. A further numerical study would be necessary to correct these optimal values but the resistive shunts show here their best asset: their low sensitivity. Even if the electrical circuits are not fully optimal, but tuned with a simple methodology, the system's efficiency is proved, when the piezoelectric effective coupling coefficients have been optimized.

\section{Conclusion}

With the necessity of designing new highly performing structures able access severe requirements, technical innovations to control vibrations have to be considered and studied. Some critical vibrating modes can put forward in many applications. For rotor design, these modes are linked to the blade aspect ratios and of course to the energy efficiency of the considered system. By developing a suitable design methodology for damping low order modes by only using simple shunted piezoelectric patches, we relax dynamical constraints and develop new designs for increasing systems efficiency.

The potential of such shunted piezoelectric systems to damp mechanical system is very interesting. Indeed the experimentally obtained damping ratios are as good as expected from the used multiphysics models. The purely passive method seems so to conclude experimentally to a very large damping addition (almost $2 \%$ of first mode damping ratio and about $25 \mathrm{~dB}$ attenuation with a PMN-33PT only shunted through a resistance), which is actually globaly efficient enough to prevent instability from aerodynamics coupling for example. The negative capacity circuit presents better results, however it can present some difficulties to be adjusted correctly. The passive control remains also always stable and can be adapted more easily to a muti-modal damping with several piezoelectric element correctly adjusted and wisely localised on the structure. For a complex geometry, the theoretical model is certainly to crude to represent fairly enough a complex system and will be soon enriched if the experimental perspectives being to be able to implement a passive control on fan blades or diskassemblies (Agnes 1999)for example. The aim of our futur studies will be to prevent fluttering phenomena from appearing and to push as far as possible the aerodynamics limits within the material resistance frontiers thanks to the optimisation premiss guidelines.

\section{References}

Agnes G. S., “ Active/passive piezoelectric vibration suppression”, in C. D. Johnson (ed.), Proc. SPIE Vol. 2193, p. 24-34, Smart Structures and Materials 1994: Passive Damping, Conor D. Johnson; Ed., p. 24-34, May, 1994.

Agnes G. S., "Piezoelectric coupling of bladed-disk assemblies", in T. T. Hyde (ed.), Proc. SPIE Vol. 3672, p. 94-103, Smart Structures and Materials 1999: Passive Damping and Isolation, T. Tupper Hyde; Ed., p. 94-103, June, 1999. 
Banks H., Smith R., Wang Y., Smart material structures Modeling Estimation and Control, Masson and Wiley, 1996.

Beck B., Cunefare K. A., Ruzzene M., “ Broadband Vibration Suppression Assessment of Negative Impedance Shunts”, in ASME (ed.), Proceedings of SMASISO8, 2008.

Becker J., Fein O., Maess M., Gaul L., “Finite element-based analysis of shunted piezoelectric structures for vibration damping”, Computers and Structures, vol. 84, p. 2340-2350, 2006.

Behrens S., Fleming A., Moheimani S., " New method for multiple-mode shunt damping of structural vibration using a single piezoelectric transducer", in D. Inman (ed.), Proc. SPIE Vol. 4331, p. 239-250, Smart Structures and Materials 2001: Damping and Isolation, Daniel J. Inman; Ed., p. 239-250, July, 2001.

Benjeddou A., "Advances in Piezoelectric Finite Element Modeling of Adaptive Structural Elements : a Survey”, Computers and Structures, vol. 76, p. 347-363, 2000.

Bernadou M., Haenel C., “ Modelisation and Numerical Approximation of Piezoelectric Thin Shell. Part II : Approximation by Finite Element Methods and Numerical Experiments", Comput. Method. Appl. Mech. Engrg., vol. 192, p. 4045-4073, 2003.

Cao V., Schmidt V., Cao W., Rui Z., Luo H., “Elastic, piezoelectric and dielectric properties”, Journal of Applied Physics, vol. 96, p. 549-554, 2004.

Casadei F., Beck B., Ruzzene M., " Vibration Control of Plates Featuring Periodic Arrays of Hybrid Shunted Piezoelectric Patches", in SPIE (ed.), Proceedings of SPIE - Smart Structures and Materials, 2009.

Chevallier G., Ghorbel S., Benjeddou A., " A benchmark for free vibration and effective coupling of thick piezoelectric smart structures”, Smart Mater. Struct, vol. 17, p. 065007, 2008.

Collet M., "Shape optimization of piezoelectric sensors dealing with spill-over instabilities", IEEE Transactions on Control System Technology, vol. 9, n 4, p. 654-663, 2001.

Collet M., Cunefare K., “ Modal Synthesis and Dynamical Condensation Methods for Accurate Piezoelectric Systems Impedance Computation”, Journal of Intelligent Material Systems and Structures, vol. 19, $\mathrm{n}^{\circ}$ 11, p. 1251-1269, 2008.

Collet M., Cunefare K., Ichchou N., “ Wave Motion Optimization in Periodically Distributed Shunted Piezocomposite Beam Structures”, Journal of Intelligent Material Systems and Structures, vol. 20, $\mathrm{n}^{\circ}$ 7, p. 787-808, 2009.

Collet M., Walter V., Delobelle P., “ Active Damping of a Micro-Cantilever Piezo-Composite Beam", Journal of Sound and Vibration, vol. 260(3), p. 453-476, 2003.

Corr L., Clark W., “ Comparison of lowfrequency piezoelectric switching shunt techniques for structural damping", Journal of Smart Material and Structrues, vol. 11, n 3, p. 370-376, 2002.

Crawley E., "Intelligent structures for aerospace: a technology overview and assessment", AIAA Journal, vol. 32, p. 1689-1699, 1994.

Cross C., Fleeter S., " Shunted piezoelectrics for passive control of turbomachine blading flowinduced vibrations”, Smart Material Structures, vol. 11, p. 239-248, April, 2002.

Cunefare K., “Negative capacitance shunts for vibration suppression: wave based tuning and reactive input power", Proceedings of Active 2006, 2006.

dell'Isola F., Maurini C., Porfiri M., “ Passive damping of beam vibrations through distributed electric networks and piezoelectric transducers: prototype design and experimental validation”, Smart Material Structures, vol. 13, p. 299-308, April, 2004. 
Fernadez A., Pouget J., " Analytical and Numerical Modelling of Laminated Composites with Piezoelectric Elements”, Journal of Intl Mat Syst and Struc, vol. 15, p. 753-761, 2004.

Fleming A., Belirens S., Moheimani S., "Synthetic impedance for implementation of piezoelectric shunt-damping circuits", Electronics Letters, vol. 36, n 18, p. 1525-1526, 2000.

Fleming A. J., Behrens S., Moheimani S. O. R., " Reducing the inductance requirements of piezoelectric shunt damping systems", Smart Materials and Structures, vol. 12, n ${ }^{\circ} 1, \mathrm{p} .57$ 64, 2003.

Fleming A. J., Moheimani S. O. R., “ Improved Current and Charge Amplifiers for Driving Piezoelectric Loads, and Issues in Signal Processing Design for Synthesis of Shunt Damping Circuits", Journal of Intelligent Material Systems and Structures, vol. 15, n 2, p. 77-92, 2004.

Fukada E., Date M., Kimura K., " Sound isolation by piezoelectric polymer films connected with negative capacitance circuits", Proceedings of 11th International Symposium on Electrets, vol. 1, p. 223 - 226, 2002.

Ha S., "Finite element analysis of sandwich plates : an overview”, Comp Struc, vol. 37, p. 1-21, 1990.

Hac A., Liu L., "Sensor and Actuator Location in Motion Control of Flexible Structures", Journal of Sound and Vibration, vol. 167(2), p. 239-261, 1993.

Hagood N. W., von Flotow A. H., " Damping of structural vibrations with piezoelectric materials and passive electrical networks", Journal of Sound and Vibration, vol. vol 146, p. 243268, 1991.

IEEE, IEEE Standard on Piezoelectricity, ANSI/IEEE Std 176-1987, 1988.

Kogl M., Bucalem M., “ Analysis of Smart Laminates using Piezoelectric MITC Plate and Shell Elements", Computers and Structures, vol. 83, p. 1153-1163, 2005.

Lagarias J., Reeds J. A., Wright M. H., Wright P. E., “ Convergence Properties of the NelderMead Simplex Method in Low Dimensions", SIAM Journal of Optimization, vol. 9, $\mathrm{n}^{\circ} 1$, p. 112-147, 1998.

Lee C., " Theory of Laminated Piezoelectric Plates for the Design of Distributed Sensors/Actuators. Parts I,II”, J.Acoust. Soc. Am, vol. 87(3), p. 1144-1157, 1990.

Lee C., Chiang W., O’Sullivan T., “ Piezoelectric Modal Sensor/Actuator Pairs for Critical Active Damping Vibration Control”, Journal of Acoustical Society of America, vol. 90(1), p. 374-384, 1991.

Lee C., Moon F., “Laminated Piezopolymer Plates for Torsion and Bending Sensors and Actuators", J. Acoust. Soc. Am, vol. 87(3), p. 2432-2439, 1989.

Lin M., Abatan A., Rogers C., " Application of commercial finite element codes for the analysis of induced strain-actuated structures”, J Intell Mater Syst Struct, vol. 5, p. 869-875, 1994.

Mackerle J., "Finite element linear and nonlinear static and dynamic analysis of structural elements: a bibliography (1992-1995)", Engrg Computations, vol. 14, p. 347-440, 1997.

Maurini C., dell'Isola F., Pouget J., “ On Model of Layered Piezoelectric Beam for Passive Vibration Control", Journal de Physique IV, vol. 115, p. 307-316, 2004.

Moheimani S., Fleming A., Piezoelectric transducers for vibration control \& damping, (Advances in industrial control), Springer, 2006.

Moheimani S., Fleming A., Behrens S., " Highly resonant controller for multimode piezoelectric shuntdamping”, Electronics Letters, vol. 37, n 25, p. 1505-1506, 2001. 
Monnier P., Collet M., “Definition of the Mechanical Design Parameters to Optimize Efficiency of Integraol Force Feedback Active Damping Strategy", Journal Structural Control and Health Monitoring, vol. 12, p. 65-89, 2005.

Monnier P., Collet M., Piranda J., “ Definition of mechanical design parameters to optimize efficiency of integral force feedback", Structural Control and health monitoring, vol. 12, p. 65-89, October, 2004.

Nelson P., Elliott S., Active Control of Sound, Pub. Academic Press, London, San Diego, 1992.

Noor A., "Bibliography of books and monographs on finite element technology", Appl Mech Rev, vol. 44, p. 307-317, 1991.

Park C., Baz A., " Vibration control of beams with negative capacitive shunting of interdigital electrode piezoceramics", Journal of Vibration and Control, vol. 11, p. 331-346, 2005.

Park J., Palumbo D., “ A New approach to Identify Optimal of Shunting Elements for Maximum Damping of Structural Vibration Using Piezelectrical Patches", Active 2004, Institute of Noise Control Engineers, p. 4-34, 2004.

Preumont A., Vibration control of structures : An introduction, Kluwer, 1997.

Rao S., Sunar M., "Piezoelectricity and its use in the disturbance sensing and control of flexible structures: a survey", Appl Mech Rev, vol. 47, p. 113-123, 1994.

Rusovici R., Dosch J., Lesieutre G., “ Design of a single-crystal piezoceramic vibration”, Journal of Intelligent Material Systems and Structures, vol. 13, p. 705-712, November, 2002.

Saravanos D., Heyliger P., Hopkins D., " Layerwise mechanics and finite element for the dynamic analysis of piezoelectric composite plates", Int Jour Solids Struct, vol. 34, p. 359-378, 1997.

Tanaka N., Kikushima Y., " Optimal vibration feedback control of an Euler-Bernouilli beam: Toward realization of the active skin method", Journal of Vibration and Acoustics, Transactions of the ASME, vol. 121(2), p. 174-182, 1999.

Tanaka N., Sakano H., “ Cluster power flow control of distributed-parameter planar structure for generating a vibration-free zone", Smart Materials and Structures, vol. 16, p. 47-56, 2007.

Thorp O., Ruzzene M., Baz A., " Attenuation and localization of wave propagation in rods with periodic shunted piezoelectric patches", Proceedings of SPIE - The International Society for Optical Engineering Smart Structures and Materials, vol. 4331, p. 218-238, 2001.

Tzou H., Vibration control of structures : An introduction, Kluwer, 1997.

Tzou H., Fu H., " A Study of Segmentation of Distributed Piezoelectric Sensors and Actuators, Part I: Theorical Analysis.”, Journal of Sound and Vibration, vol. 172(2), p. 247-259, 1994a.

Tzou H., Fu H., “ A Study of Segmentation of Distributed Piezoelectric Sensors and Actuators, Part II : Parametric Study and Active Vibration Controls", Journal of Sound and Vibration, vol. 172(2), p. 261-275, 1994b.

Varadan V., Lim Y., Varadan V., “ Closed loop finite-element modeling of active/passive damping in structural vibration control", Smart Materials and Structures, vol. 5, p. 685-694, 1996.

Wang S., "A Finite Element Model for the Static and Dynamic Analysis of Piezoelectric Bimorph”, Int Journal of Solid and Structures, vol. 41, p. 4075-4096, 2004. 
Wu S., Bicos A., " Structural vibration damping experiments using improved piezoelectric shunts", in L. P. Davis (ed.), Proc. SPIE Vol. 3045, p. 40-50, Smart Structures and Materials 1997: Passive Damping and Isolation, L. Porter Davis; Ed., p. 40-50, May, 1997.

Yang H., Saigal S., Liaw D., “ Advances of thin shell finite elements and some applications Vers I", Smart Struct Mat, vol. 35, p. 481-504, 1996. 